\title{
Characterization of ZDDP and Ionic Liquid Tribofilms on Non-Metallic Coatings Providing Insights of Tribofilm Formation Mechanisms
}

\author{
Jun $\mathrm{Qu}^{1, *}$, Harry M. Meyer $\mathrm{III}^{1}$, Zhen-Bing Cai ${ }^{1,2}$, Cheng Ma $^{1}$, Huimin $\mathrm{Luo}^{3}$ \\ ${ }^{1}$ Materials Science and Technology Division, Oak Ridge National Laboratory, USA \\ ${ }^{2}$ Tribology Research Institute, Key Lab of Advanced Technologies of Materials, Southwest Jiaotong \\ University, China \\ ${ }^{3}$ Energy \& Transportation Science Division, Oak Ridge National Laboratory, USA
}

\begin{abstract}
Lubricant anti-wear additives are known to chemically interact with metallic surfaces to form a selfhealing, wear-protection tribofilm. Their interactions with non-metallic surfaces are however less understood. Here we report recent findings on whether and how a zinc dialkyldithiophosphate (ZDDP) and a phosphonium-organophosphate ionic liquid (IL) form tribofilms on three hard coatings, $\mathrm{AlMgB}_{14^{-}}$ $\mathrm{TiB}_{2}, \mathrm{TiB}_{2}$, and diamond like carbon (a-C:H DLC), when sliding against a steel ball. Systematic characterization was conducted on the coating wear scars including top surface morphology imaging and elemental mapping, layer-by-layer chemical analysis, and cross section nanostructural examination. The ZDDP and IL tribofilms on the boride coatings are up to 50-70 nm thick with $75-80 \%$ surface coverage while the tribofilms on DLC were $<25 \mathrm{~nm}$ thick and only covered 20-30\% of the contact area. The presence of iron compounds in the tribofilms suggests a critical role for wear debris in tribofilm formation. Oxidation products of $\mathrm{TiB}_{2}$ were detected in the tribofilms, while no involvement of the DLC surface in tribofilm formation was observed. Results suggest that wear debris digestion and contact surface reaction both are critical in tribofilm formation: the former process is responsible in forming the bulk of the tribofilm and the latter provides strong bonding of the tribofilm to the contact surface.
\end{abstract}

Keywords: ZDDP, ionic liquid, coating, boride, DLC, tribofilm

\footnotetext{
* Corresponding author, P.O. Box 2008, MS-6063, Oak Ridge, TN 37830-6063, tel: (865) 576-9304, fax: (865) 5744913, qujn@ornl.gov
} 


\section{Introduction}

A number of non-metallic hard coatings have been developed and commercialized in last two decades and many of them are claimed to possess superior tribological properties [1,2]. If applied to mating parts, the low friction and/or high wear-resistant hard coatings may potentially improve efficiency and durability of machinery such as internal combustion engines and hydraulic systems. However, to date, typical bearing components, such as engine piston rings and cylinder bores, cams and tappets, and gears, are still overwhelmingly dominated by ferrous alloys. While cost remains a concern, the lack of understanding of the compatibility between the non-metallic coatings and lubricant chemistry is one of the major technical barriers.

A commercial lubricant is composed of one or more base oils and several categories of additives including anti-wear (AW), friction modifier, viscosity modifier, antioxidant, detergent, dispersant, etc [3]. Specifically, AW agents, such as the most common zinc dialkyldithiophosphate (ZDDP) [4,5] in engine oils, play a key role in controlling the wear in boundary and mixed lubrication. ZDDP is known to form a self-healing, wear-protection tribofilm on ferrous and other hard alloy surfaces [5-10]. However, the ZDDP tribofilm formation mechanisms [4-8] remain controversial and the interactions between ZDDP and carbon or ceramic surfaces are even less understood [11-14]. Ionic liquids (ILs) are currently of great interest for lubrication in both fundamental and applied research [15-19]. While the majority of literature has been focused on the tribological behavior and tribofilm formation of ILs for metal surfaces [16-20], some reported to apply fluorine-containing ILs as lubricants for ceramic coatings $[15,21,22]$. Our group recently developed new groups of halogen-free, oil-soluble ILs composed of quaternary structured phosphonium cations and various surfactant-type anions including organophosphate, phosphinate, and carboxylate [23,24]. Such phosphonium-based ILs, when used as oil additives, have demonstrated superior wear protection for metallic surfaces [25-30], but their interactions with non-metallic materials are little known except a report of no IL tribofilm observed on silicon carbide [14].

In this study, we used two AW additives, a conventional secondary ZDDP and a phosphoniumorganophosphate $\mathrm{IL}$, in a base oil to lubricate three hard coatings, $\mathrm{AlMgB}_{14}-\mathrm{TiB}_{2}, \mathrm{TiB}_{2}$, and diamond like 
carbon (DLC) against a bearing steel ball. $\mathrm{TiB}_{2}$ [31-34] and DLC [35-38] are among the most successful commercial hard coatings, while the $\mathrm{AlMgB}_{14}-\mathrm{TiB}_{2}$ nanocomposite coating [39-43] was more recently developed with promising tribological behaviour. Comprehensive characterization was carried out on the coating wear scars to reveal the surface coverage, film thickness, nanostructure, and composition of the ZDDP and IL tribofilms. Results provide fundamental insights of the tribofilm formation.

\section{Materials and Experimental Procedure}

Three coatings, $\mathrm{AlMgB}_{14}-\left(50\right.$ vol.\%) $\mathrm{TiB}_{2}$ (denoted as $\left.\mathrm{BAM}\right), \mathrm{TiB}_{2}$, and hydrogenated DLC (a-C:H), were deposited on hardened M2 tool steel using physical vapor deposition (PVD). The M2 steel substrate coupon has a top surface of $12 \times 13 \mathrm{~mm}^{2}$ and a thickness of $3.2 \mathrm{~mm}$, a microindentation Knoop's hardness (HK) of 9.4 GPa, and a surface roughness of $0.18 \mu \mathrm{m}$ in $R_{\mathrm{a}}$. The two boride coatings were produced using a CemeCon CC800/8 PVD system at Eaton Corp., while the DLC coating was provided by HEF USA. The BAM and $\mathrm{TiB}_{2}$ coatings have thicknesses in the ranges of 2.5-3.0 and 2.0-2.5 $\mu \mathrm{m}$ and Knoop microindentation hardness (HK) of 29.1 and $21.2 \mathrm{GPa}$, respectively. The DLC coating is $\sim 3.5 \mu \mathrm{m}$ thick and its hardness is $18.7 \mathrm{GPa} \mathrm{HK}$. According to the vendor, the a-C:H DLC contains $\sim 20 \% \mathrm{H}$ and $\sim 80 \%$ C. The $\mathrm{C}$ is composed of $20-30 \%$ of $\mathrm{SP}^{3}$ and $70-80 \%$ of $\mathrm{SP}^{2}$. All three coated surfaces have a similar roughness of $0.16 \mu \mathrm{m}$ in $R_{\mathrm{a}}$. The Knoop microindentation was conducted on a Buehler Micromet ${ }^{\circledR}$ $2100^{\mathrm{TM}}$ at a $100 \mathrm{~g}-\mathrm{f}$ load and the roughness was measured using Taylor Hobson Talysurf 120 Stylus Profiling Instrument. The coatings' nominal composition, thickness, hardness, and roughness are summarized in Table 1. Cross sectional views of the coatings are shown in Fig. 1. The microstructure images and elemental maps were produced using scanning electron microscopy (SEM) and energydispersive x-ray spectroscopy (EDS), respectively, using a field-emission Hitachi S-4800 SEM. The SEM and EDS observations agree well with the nominal coating thicknesses and compositions. No interlayer was detected for any of the coatings. 
Table 1. Key properties of coatings.

\begin{tabular}{lcccc}
\hline Coating & Composition & Thickness $(\mu \mathrm{m})$ & HK hardness $(\mathrm{GPa})$ & Roughness $(\mu \mathrm{m})$ \\
\hline $\mathrm{BAM}$ & $\mathrm{AlMgB}_{14}+50 \mathrm{vol} \% \mathrm{TiB}_{2}$ & $2.5-3.0$ & 29.1 & 0.16 \\
\hline $\mathrm{TiB}$ & $\mathrm{TiB}_{2}$ & $2.0-2.5$ & 21.2 & 0.16 \\
\hline $\mathrm{DLC}$ & $\mathrm{a}-\mathrm{C}: \mathrm{H}$ & $\sim 3.5$ & 18.7 & 0.16 \\
\hline
\end{tabular}
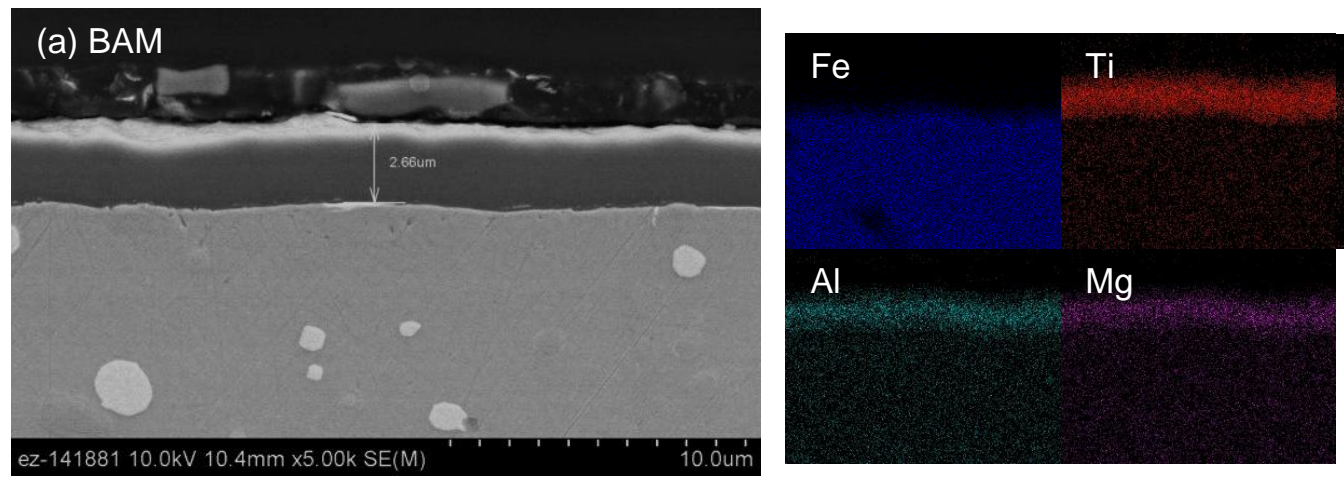

\section{B}
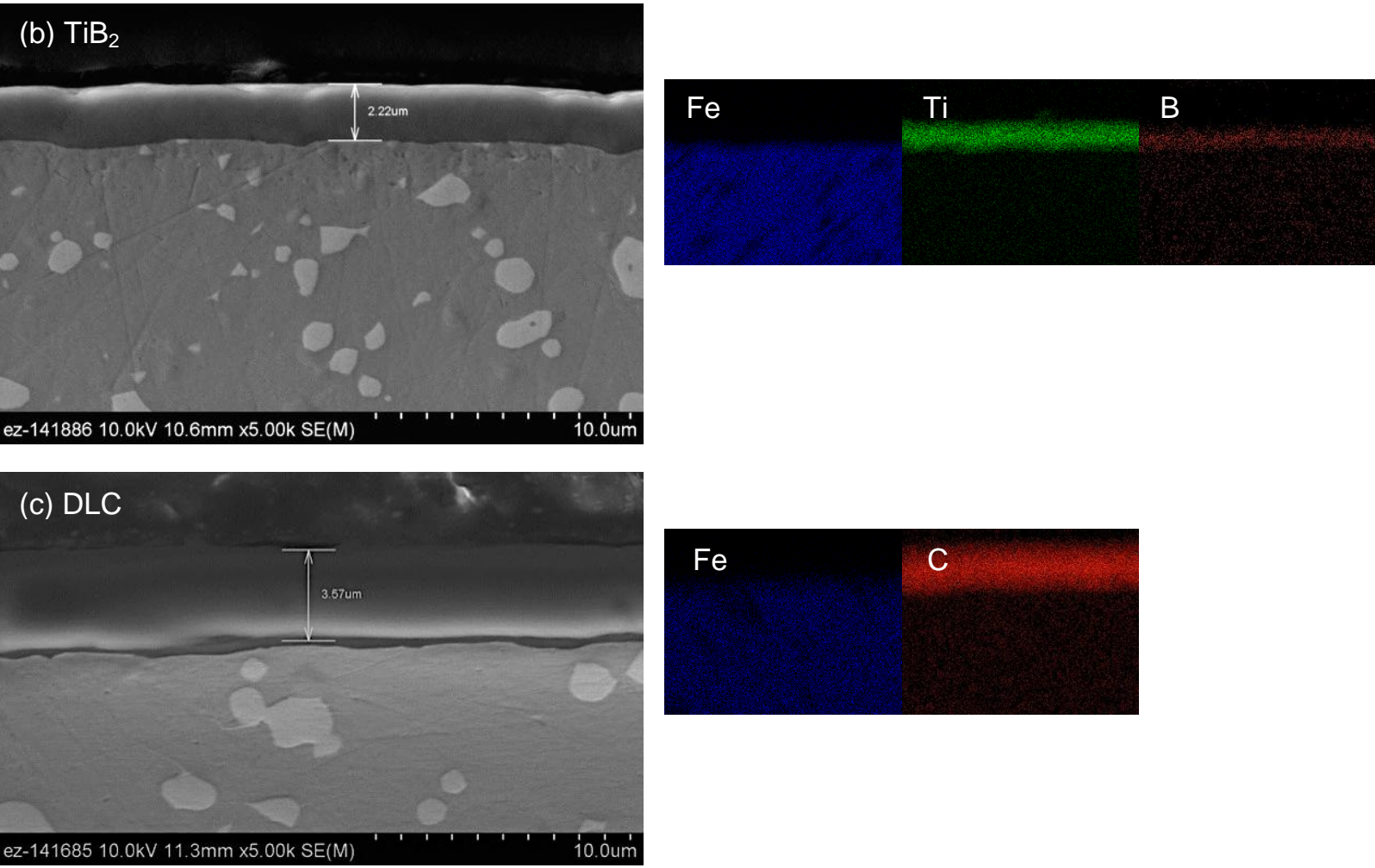

Fig. 1. SEM images and EDS element maps of polished cross sections of BAM, $\mathrm{TiB}_{2}$ and DLC coatings.

Two AW additives, a commercial secondary ZDDP and an IL, trihexyltetradecylphosphonium bis(2ethylhexyl) phosphate $\left(\left[\mathrm{P}_{66614}\right][\mathrm{DEHP}]\right)$, were selected to study the tribofilm formation on the three above-described coatings. The ZDDP sample was kindly provided by the Lubrizol Company, while the IL 
was synthesized at Oak Ridge National Laboratory (ORNL). The starting materials for making the IL were bis(2-ethylhexyl) phosphate and tetradecyltrihexylphosphonium bromide purchased from SigmaAldrich, and the synthesis had previously been described in $[26,27]$. [ $\left.\mathrm{P}_{66614}\right][\mathrm{DEHP}]$ has mutual miscibility with non-polar lubricating oils, high thermal stability, non-corrosive to ferrous alloys, low contact angles with metal surfaces, and excellent anti-wear behavior for ferrous alloys [14,26,27]. The molecular structures of the ZDDP and IL are illustrated in Fig. 2, and their key physical and rheological properties are summarized in Table 2 [26,27]. Both ZDDP and IL have been reported to generate a protective tribofilm on metallic bearing surfaces, however their tribofilm formability and mechanism on non-metallic coatings are little known and thus were investigated in this study. The ZDDP and IL were added to a SAE 0W-30 [44] base oil (BO) at the same treat rate of 1.0 wt.\% to produce two test lubricants, denoted as BO+ZDDP and BO+IL, respectively. The viscosity of the base oil and oil-AW blends are listed in Table 2 [14], which suggests little change induced by the 1\% addition of ZDDP or IL.

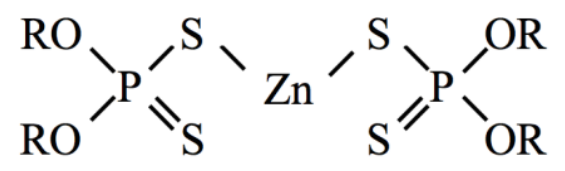

(a) Secondary ZDDP (R: branched alkyl)

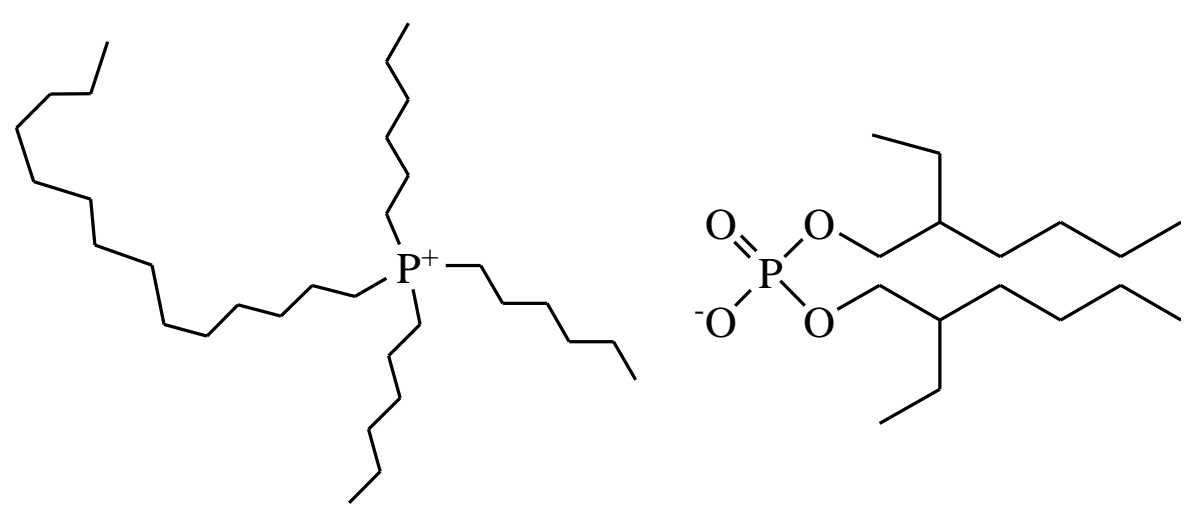

(b) $\left[\mathrm{P}_{66614}\right][\mathrm{DEHP}]$

Fig. 2. Molecular structures of the ZDDP and IL [P $\left.\mathrm{P}_{66614}\right][\mathrm{DEHP}]$. 
Table 2. Thermal stability, density, and viscosity of AW additives and oil-AW blends [14,26,27].

\begin{tabular}{lccccc}
\hline & $\begin{array}{c}\text { Decomposition } \\
\text { temp. }\left({ }^{\circ} \mathrm{C}\right)\end{array}$ & $\begin{array}{c}\text { Density @ } 23 \\
{ }^{\circ} \mathrm{C}(\mathrm{g} / \mathrm{ml})\end{array}$ & \multicolumn{3}{c}{ Viscosity $(\mathrm{cP})$} \\
\cline { 4 - 6 } $\mathrm{ZDDP}^{\#}$ & $\sim 200$ & 1.20 & $>1500^{\circ} \mathrm{C}$ & $40{ }^{\circ} \mathrm{C}$ & $100{ }^{\circ} \mathrm{C}$ \\
\hline$\left[\mathrm{P}_{66614}\right][\mathrm{DEHP}]$ & $\sim 350$ & 0.91 & 938 & 380 & 44.8 \\
\hline $0 \mathrm{~W}-30$ base oil (BO) & $\sim 250$ & 0.82 & 26.6 & 13.8 & 3.12 \\
\hline $\mathrm{BO}+1$ wt.\% ZDDP (BO+ZDDP) & Not measured & 0.82 & 26.6 & 13.8 & 3.13 \\
\hline $\mathrm{BO}+1$ wt.\% IL (BO+IL) & Not measured & 0.82 & 26.8 & 13.9 & 3.13 \\
\hline${ }^{\#} A$ solution of ZDDP in mineral oil containing 5-10\% oil. & & & & \\
${ }^{*}$ Above the measuring range of the viscometer. & & & &
\end{tabular}

Using a ball-on-flat reciprocating sliding test, the $\mathrm{BAM}, \mathrm{TiB}_{2}$ and $\mathrm{DLC}$ coatings were rubbed against an AISI 52100 steel ball (10 mm diameter) lubricated by BO+ZDDP or BO+IL. Tests were carried out under a $54 \mathrm{~N}$ load and an oscillation frequency of $10 \mathrm{~Hz}$ with a stroke of $10 \mathrm{~mm}$, at room temperature ( $23 \square$ C) for $1000 \mathrm{~m}$ of sliding. The contact interface was fully submerged in the lubricant. At least two repeat tests were conducted at each condition. The maximum (stroke midpoint) central lubricant film thickness $\left(h_{c}\right)$ was estimated to be $<0.05 \mu \mathrm{m}$ using the Hamrock and Dowson formula [45]. The composite roughness of the ball and flat $\left(=\sqrt{R_{q, \text { ball }}^{2}+R_{q, \text { flat }}^{2}}\right)$ was $\sim 0.22 \mu \mathrm{m}$. The calculated maximum $\lambda$-ratio $\left(h_{\mathrm{c}} / \sigma\right)$ was calculated $<1$, indicating boundary lubrication [45]. The tangential (friction) force was measured in situ by a piezoelectric load sensor and the friction coefficient was calculated by normalizing the friction force by the normal load. The worn surfaces of the ball and plate were ultrasonically cleaned using isopropanol right after each test. The wear volume was quantified using a Wyko ${ }^{\mathrm{TM}}$ NT9100 white light interferometer.

Morphology of the wear scars on coatings was examined using SEM. Auger electron spectroscopy (AES) was used for surface elemental mapping (qualitative only) of the ZDDP and IL tribofilms on the three coatings. Ar ion sputtering was used to allow layered element mapping of the top surface as well as after 30 and 120 s of sputtering. The PHI 680 Scanning Auger Nanoprobe uses a Schottky field emission electron gun that provides a spatial resolution of less than $30 \mathrm{~nm}$ when operated at $10 \mathrm{kV}$. The placement the electron gun column along the axis of the cylindrical mirror analyzer provides reliable analysis of 
multiple sample types, including samples with rough or irregular surface topography. Survey spectra provided an overall picture of what elements were present at the surface and allowed for tuning the electron detector to those elements for 2-D mapping. An Ar-ion gun, operated at a beam voltage of $2 \mathrm{kV}$ and a beam current of 1 microA, was used to sputter etch the outer surface to provide a comparison of the as received surface. AES data analysis was performed using the Phi MultiPak (v.9.2) software package. A Hitachi NB5000 focused ion beam (FIB) system with a gallium source was used to extract a thin crosssection of the tribofilms on the coatings for transmission electron microscopy (TEM) examination. A carbon film and then a tungsten layer were deposited onto the wear scar before the FIB process to protect the tribofilm. The TEM system used was an aberration-corrected FEI Titan S 80-300 TEM/STEM equipped with a Gatan Image Filter Quantum-865.

X-ray photoelectron spectroscopy (XPS) analysis was carried out on a Thermo Scientific K-Alpha XPS instrument. The x-rays used were monochromatic Al-k $\alpha$ photons, and photo emitted electrons were analyzed with a hemispherical energy analyzer. For the insulating boride coatings, a charge-compensation system was employed to prevent surface charging during analysis. The charge compensation system uses both low energy electrons and low energy Ar-ion to alleviate surface charging. The binding energy of position adventitious carbon $(284.6 \mathrm{eV})$ is verified to check the operation of the charge compensation system. Surface compositions were calculated by measuring peak areas of the primary core levels for all elements present and normalizing the peak areas using tabulated sensitivity factors. Composition-depth profiles were obtained under $1 \mathrm{kV}$ ion beam energy at high a current setting. Such a condition was previously used to etch a standard $\mathrm{SiO}_{2}$ film $(100 \mathrm{~nm})$ giving a measured sputter rate of $\sim 10 \mathrm{~nm} / \mathrm{min}$, which was used here to estimate the depth. For the composition-depth profiles, peak fitting was performed for the Fe 2p3/2 peak using two features: one at $\sim 707 \mathrm{eV}$ for Fe metal and another between 709 and $711 \mathrm{eV}$ for Fe-ion (which is meant to mean reacted or oxidized Fe). This second, broader peak was allowed to shift in B.E. so that $\mathrm{Fe}^{2+}$ and $\mathrm{Fe}^{3+}$ were both "captured" in the fitting. For core level data, we show the positions of well documented chemical shifts for compounds and decide not to show detailed fitting for clarity. 


\section{Results and Discussion}

\subsection{Friction and wear results}

The friction and wear results are summarized in Table 3. The steady-state coefficient of friction (COF) is very similar ( 0.105) for the two boride coatings regardless of the lubricant. The DLC generated a slightly but consistently higher steady-state COF than the boride coatings. No measurable wear was observed on any of the coating surfaces after $1000 \mathrm{~m}$ of sliding, but their counterface (steel balls) experienced material loss to various extents. There was a clear trend: for a given coating, the ball was worn less in BO+IL than in BO+ZDDP, which once again suggests superior wear protection for $\left[\mathrm{P}_{66614}\right][\mathrm{DEHP}]$ in lubricating steel compared to ZDDP (in line with the observations in previous reports $[14,27])$. Characterization of the tribofilms on the three non-metallic coatings is presented below with fundamental insights for the ZDDP and IL tribofilm formation mechanisms.

Table 3. Summary of friction and wear results

\begin{tabular}{|c|c|c|c|c|c|}
\hline \multirow[b]{2}{*}{ Coating } & $\begin{array}{l}\text { Wear volume of coating } \\
\left(\times 10^{6} \mu \mathrm{m}^{3}\right)\end{array}$ & \multicolumn{2}{|c|}{$\begin{array}{l}\text { Wear volume of steel ball } \\
\qquad\left(\times 10^{6} \mu \mathrm{m}^{3}\right)\end{array}$} & \multicolumn{2}{|c|}{$\begin{array}{c}\text { Steady-state friction } \\
\text { coefficient }\end{array}$} \\
\hline & BO+ZDDP $\quad$ BO+IL & BO+ZDDP & $\mathrm{BO}+\mathrm{IL}$ & $\mathrm{BO}+\mathrm{ZDDP}$ & $\mathrm{BO}+\mathrm{IL}$ \\
\hline BAM & \multirow{3}{*}{ Not measurable } & $3.79^{ \pm 1.26}$ & $1.85^{ \pm 0.15}$ & $0.105^{ \pm 0.001}$ & $0.105^{ \pm 0.002}$ \\
\hline $\mathrm{TiB}_{2}$ & & $3.87^{ \pm 0.29}$ & $0.68^{ \pm 0.04}$ & $0.104^{ \pm 0.001}$ & $0.105^{ \pm 0.000}$ \\
\hline DLC & & $2.85^{ \pm 0.20}$ & $1.32^{ \pm 0.05}$ & $0.110^{ \pm 0.001}$ & $0.113^{ \pm 0.002}$ \\
\hline
\end{tabular}

\subsection{Characterization of tribofilms on BAM}

\subsubsection{ZDDP tribofilm on BAM}

\subsubsection{ZDDP tribofilm on BAM - SEM imaging and AES elemental mapping}

The worn surface of the BAM coating lubricated by BO+ZDDP is shown in Fig. 3a (left image). Clusters of 'bright' pad-like materials appear to cover the plateaus on the wear scar and they were gradually removed by ion sputtering, as shown in Fig. 3a (middle and right images). 
The AES multi-element mapping before and after ion sputtering (Fig. 3b) detected a $\mathrm{Zn}$ and $\mathrm{P}$ rich film on the BAM worn surface with Zn distribution matching well with the 'bright' pads on the plateaus in the SEM images (Fig. 3a). This clearly indicates that a ZDDP tribofilm was formed on the boride surface. The individual element maps after $30 \mathrm{~s}$ sputtering (Fig. 3c) provide some interesting hints on the tribofilm composition and the sources of elements:

- Zn, P, S, and C (from ZDDP): The Zn map largely matches with the O and S maps, indicating zinc oxide(s) and sulfide(s). The mismatch between $\mathrm{Zn}$ and $\mathrm{P}$ distributions suggests little zinc phospohate(s) in the tribofilm on BAM. This is distinct from the ZDDP tribofilms on steel surfaces, which usually contain a large amount of zinc phospohate(s) [5-10]. The strong correlation between the $\mathrm{C}$ and $\mathrm{P}$ maps suggests that the carbon contents in the tribofilm may not simply be carbon black from decomposed base oil or contaminant from the environment, but rather part of the organophosphate(s) (partially decomposed ZDDP [4,5]) contained in the tribofilm.

- Fe (from steel ball): The presence of Fe in the ZDDP tribofilm on BAM (that does not contain Fe) suggests that the wear debris of the steel ball was actively involved in the complex tribochemical reactions of the tribofilm formation. The Fe map matches well with the $\mathrm{O}$ and $\mathrm{P}$ maps, suggesting iron oxide(s) and phosphate(s). Such observation supports the wear particle digestion mechanism for ZDDP tribofilm formation proposed by Martin et al. [7], who also believed that iron oxides would further react with zinc phosphate(s) to produce iron phosphate(s) and zinc oxide based on chemical hardness.

- $\quad \mathbf{T i}$ (from $\mathrm{TiB}_{2}$ of $\mathbf{B A M}$ ): The distribution of Ti overlaps with that of $\mathrm{O}$, implying possible $\mathrm{TiB}_{2}$ oxidation, which was later confirmed by XPS analysis in Fig. 5b (see discussion of XPS results below). Previous work on surface oxidation of BAM by Higdon et al. [42] showed that $\mathrm{TiB}_{2}$ was oxidized while $\mathrm{AlMgB}_{14}$ remained intact. The oxidation products of $\mathrm{TiB}_{2}$ could possibly participate in the tribofilm formation. Such interactions may help on the bonding between the tribofilm and the coating surface. 

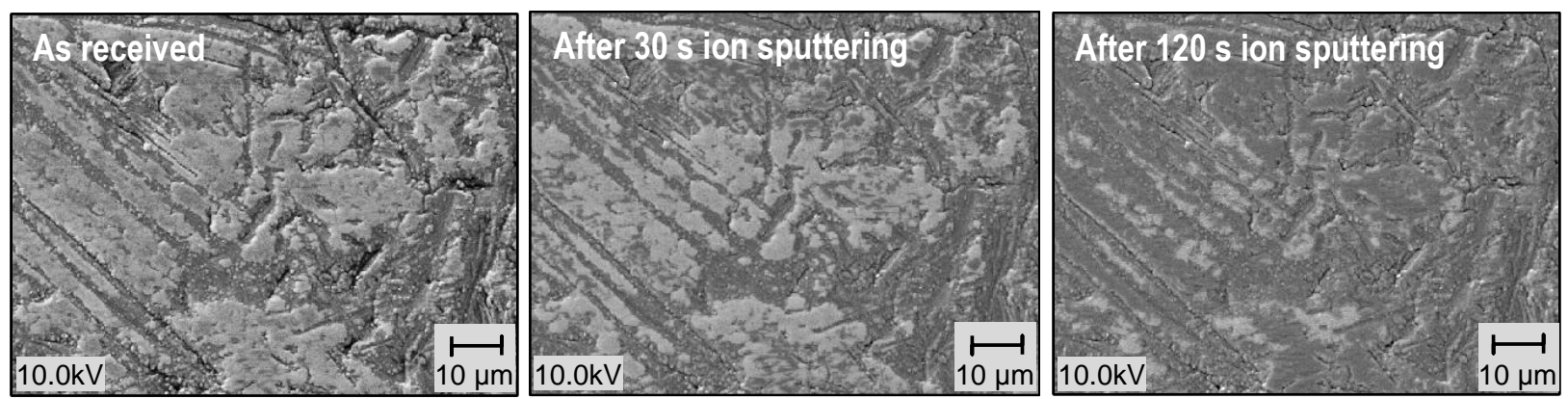

(a) ZDDP tribofilm on BAM: SEM images before and after ion sputtering
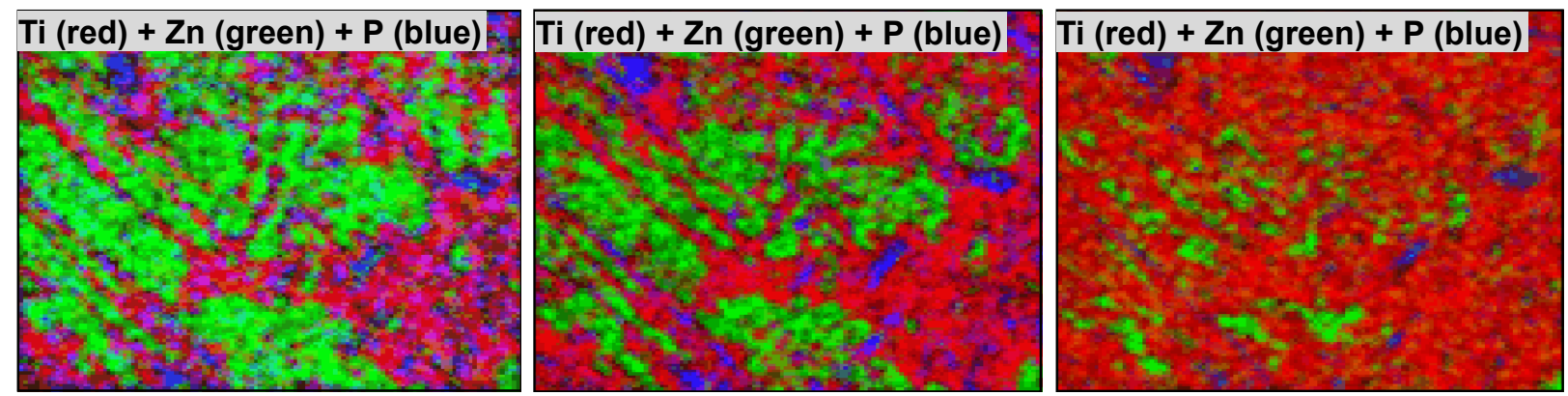

(b) ZDDP tribofilm on BAM: AES multi-element maps before and after ion sputtering
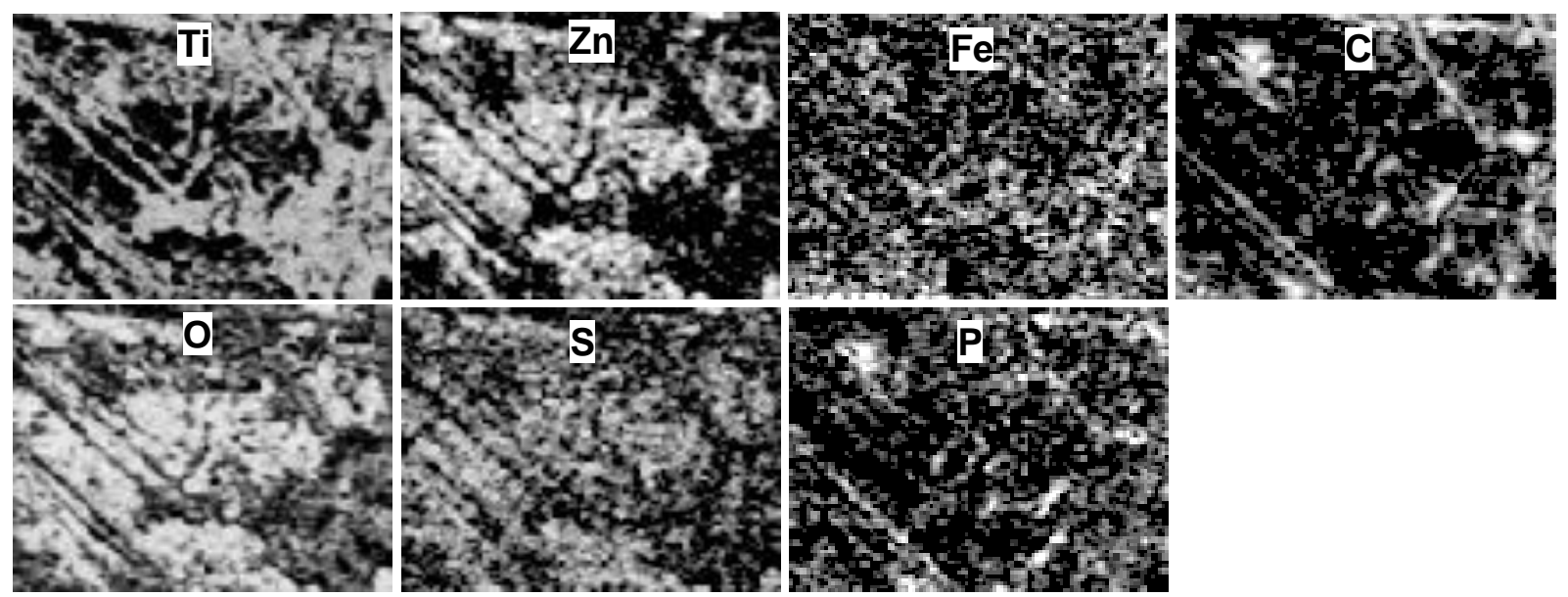

(c) ZDDP tribofilm on BAM: AES individual element maps after $30 \mathrm{~s}$ sputtering

Fig. 3. SEM and AES examination of the tribofilm on the BAM worn surface lubricated by BO+ZDDP.

\subsubsection{ZDDP tribofilm on BAM - TEM cross-sectional imaging}

Figure 4 shows the cross sectional TEM image (left) of the BAM worn surface lubricated by BO+ZDDP, which reveals a tribofilm of $\sim 50 \mathrm{~nm}$ thick and having good bonding with the BAM surface.

The fast Fourier transform (FFT) pattern (right insert in Fig. 4) calculated from a high-resolution TEM 
(HRTEM) image of the tribofilm (not shown here) clearly suggests a dominatingly amorphous nature. The nanostructure of the ZDDP tribofilm on BAM is similar to that on a metallic surface as reported in the literature $[9,10]$.

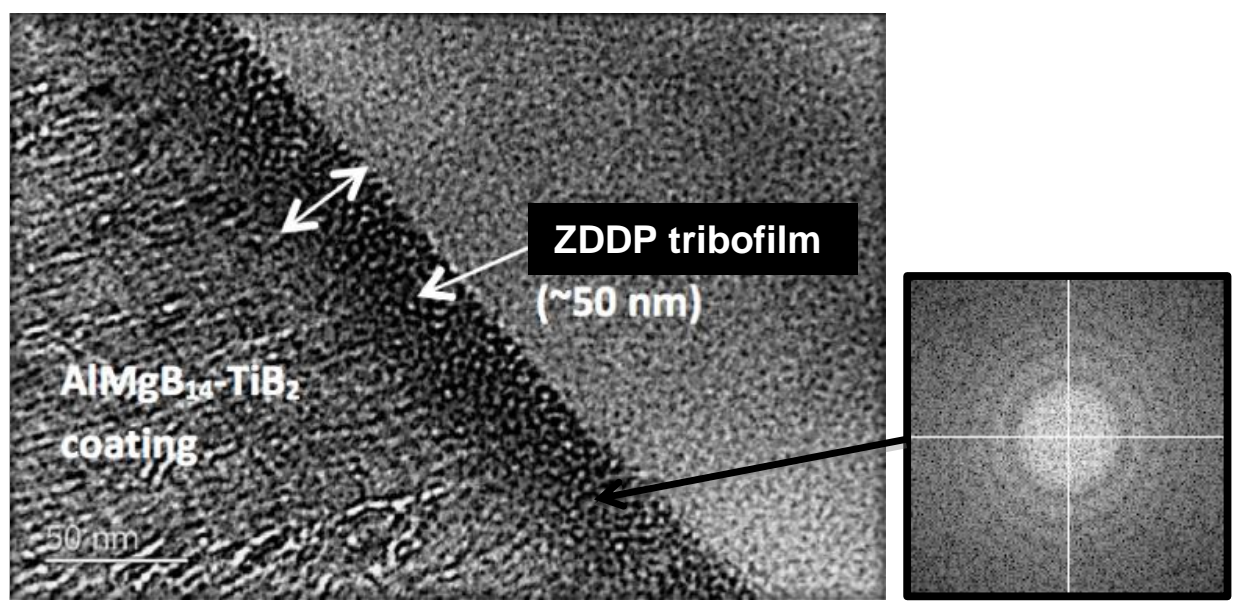

Fig. 4. Cross sectional TEM image (left) and the FFT pattern from an HRTEM image (right) revealing a 50 nm thick, amorphous tribofilm on the BAM worn surface lubricated by BO+ZDDP.

\subsubsection{ZDDP tribofilm on BAM - XPS chemical analysis}

The ZDDP tribofilm on BAM was further analyzed using XPS. The composition-depth profile and core level spectra are shown in Fig. 5. The nominal binding energies of the key elements of the materials of the contact surfaces and ZDDP are listed in Table 4 and used to identify the peaks in the experimentally acquired core spectra in Fig. 5b. XPS data confirmed some observations from AES and TEM with further insights of the ZDDP tribofilm composition on the BAM coating.

- The signature elements of a ZDDP tribofilm, Zn, P, S, and O, quickly fade with ion sputtering, as shown in Fig. 5a. The observed maximum tribofilm thickness of 50-60 nm agrees well with the $\sim 50 \mathrm{~nm}$ shown in the cross sectional TEM image (Fig. 4).

- The low concentrations of $\mathrm{B}, \mathrm{Ti}, \mathrm{Al}$, and $\mathrm{Mg}$ (BAM elements) near the top surface (Fig. 5a) confirm a high surface coverage ( $>80 \%)$ by the tribofilm, as shown in the AES element maps (Fig. 3). 
- The $\sim 45$ at. $\%$ of $\mathrm{O}, \sim 6$ at.\% of $\mathrm{P}$, and $\sim 1.5$ at.\% of S shown in the composition-depth profile in Fig. 5a (at the beginning of ion sputtering) along with their core level spectra in Fig. 5b suggest dominating metal oxide(s) and phosphate(s), and a small amount of metal sulfide(s) in the tribofilm. (Note that the reduced concentrations of tribofilm elements when sputtering progresses have little to do with the composition change but simply reflect the reduced size of the tribofilm coverage and thus increasingly exposed BAM surface area.)

- Zinc compounds seem to dominate in the tribofilm as the $\mathrm{Zn}$ concentration $(\sim 8$ at.\%) is much higher than any other metallic element (3 at.\% or less, even including the signals from the uncovered coating surface), as shown in Fig. 5a. The core level spectra in Fig. 5b clearly show a strong single peak of $\mathrm{Zn}^{2+}$.

- There is $\sim 1$ at.\% Fe (oxidized plus metallic) near the tribofilm surface as shown in Fig. 5a. The core level spectra of iron in Fig. 5b suggest that iron in the top tribofilm surface (red, as received) is primarily $\mathrm{Fe}^{3+}$ while the iron inside the tribofilm (green, after $30 \mathrm{~s}$ sputtering) mostly is in the forms of $\mathrm{Fe}^{2+}$ and $\mathrm{Fe}^{0}$. This is probably because the very top layer was further oxidized during the storage (ambient) after the tribo-test. As suggested by Martin et al. [7], iron oxide(s) may subsequently react with zinc phosphate(s) to form iron phosphate(s) and $\mathrm{ZnO}$ because $\mathrm{Fe}^{3+}$ and $\mathrm{Fe}^{2+}$ are harder Lewis acids than $\mathrm{Zn}^{2+}$ and phosphate is a hard base. The strong peak of $\mathrm{Fe}^{0}$ confirms the inclusion of metallic iron nanoparticles (unreacted wear debris from the steel ball) in the tribofilm. We suspect that the outer layer of the iron wear particles reacted to form oxide(s) and/or phosphate(s), but the core of wear particles may remain in metallic phase.

- The core spectra of $\mathrm{B}$ and $\mathrm{Ti}$ in Fig. $5 \mathrm{~b}$ clearly show oxidation products, $\mathrm{TiO}_{2}$ and borate(s), at the outer surface. After $30 \mathrm{~s}$ sputtering, the peaks of oxidation products still exist, which is at a weaker level only because of the tribofilm removal to expose more area of the coating surface. This suggests possible inclusion of the $\mathrm{TiO}_{2}$ and borate(s) in the tribofilm. There was no clear shift of Al. The shift of Mg 1s could be due to several things: the Mg 1s has a high binding 
energy, meaning low kinetic energy of the outgoing photoelectron that is easily influenced by slight charging, chemistry, etc. (The Mg 2p core level is the one most commonly selected for determining chemistry, but the signal was weak.)
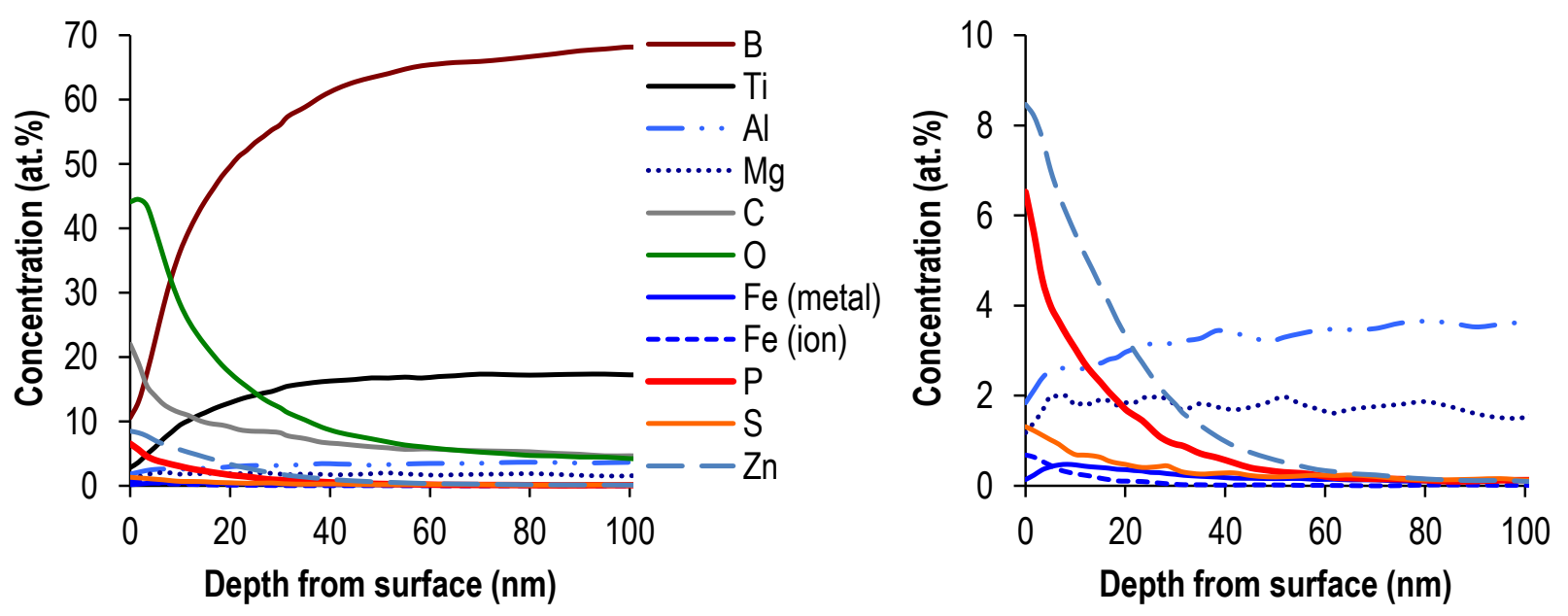

(a) ZDDP tribofilm on BAM: Composition-depth profile (right: zoomed-in)
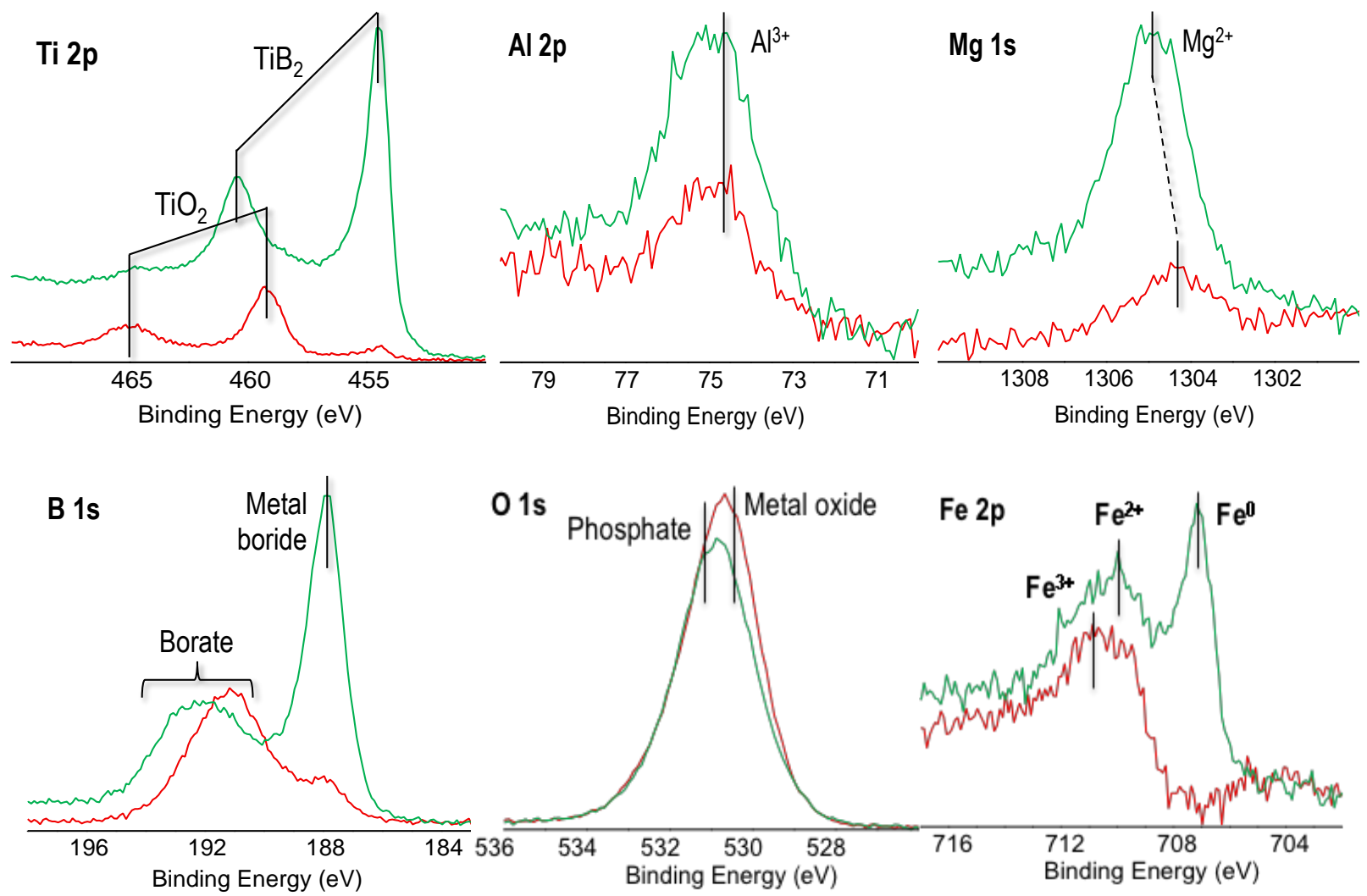

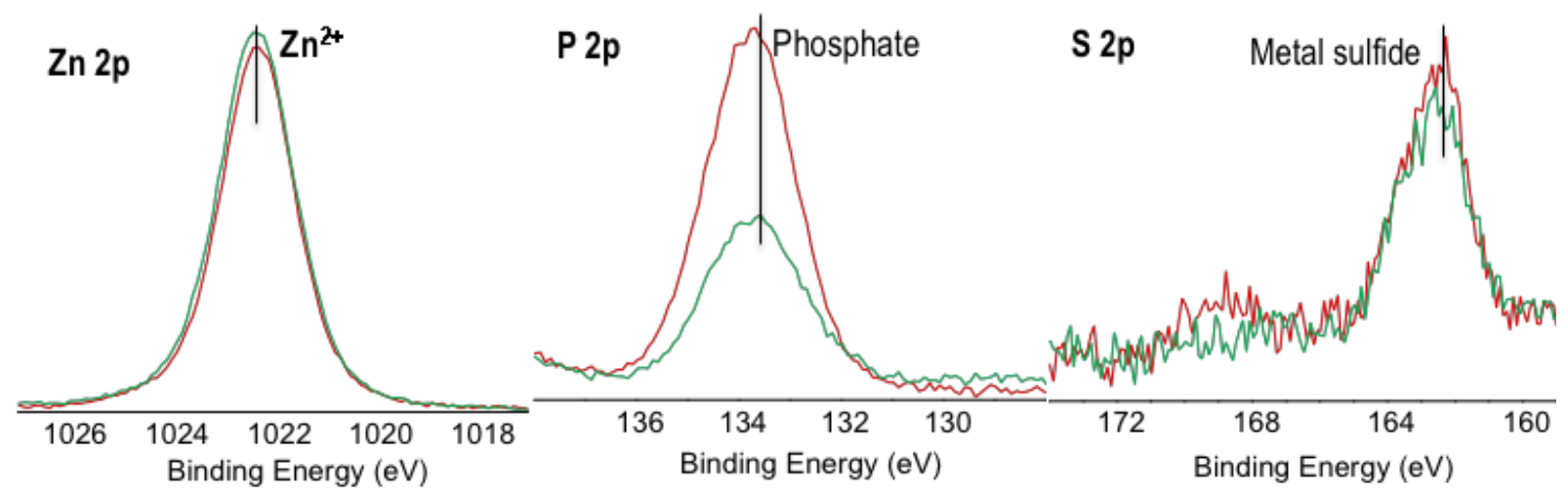

(b) ZDDP tribofilm on BAM: Core level spectra (red: as received; green: after 30 s sputtering)

Fig. 5. XPS chemical analysis of the tribofilm on the BAM worn surface lubricated by BO+ZDDP.

Table 4. Nominal XPS binding energy of key elements.

\begin{tabular}{ll}
\hline Element & Nominal binding energy $(\mathrm{eV})$ \\
\hline $\mathrm{Ti}$ & $\mathrm{Ti}^{4+}$ (oxide): 485.5 \\
& $\mathrm{Ti}^{4+}$ (boride): 454.5 \\
\hline $\mathrm{Al}$ & $\mathrm{Al}^{3+}: 74.5$ \\
\hline $\mathrm{Mg}$ & $\mathrm{Mg}^{2+}: 1303.9$ \\
\hline $\mathrm{B}$ & $\mathrm{B}$ (boride): $188.5(\mathrm{Al})$ and $187.5(\mathrm{Ti})$ \\
& $\mathrm{B}$ (borate): 192-194 \\
\hline $\mathrm{O}$ & $\mathrm{O}$ (metal oxide): 528.5-531.5 \\
& $\mathrm{O}$ (phosphate): 530.4-533.0 \\
\hline $\mathrm{Fe}$ & $\mathrm{Fe}^{0}:$ 707.0; $\mathrm{Fe}^{2+}: 709.5 ; \mathrm{Fe}^{3+}: 711.0$ \\
\hline $\mathrm{Zn}$ & $\mathrm{Zn}^{2+}: 1021.5-1022$ \\
\hline $\mathrm{P}$ & $\mathrm{P}($ phosphate): $133.0-135.0$ \\
\hline $\mathrm{S}$ & $\mathrm{S}$ (sulfate): 168.0-169.5; \\
& $\mathrm{S}($ sulfide): $161.5-163.0$ \\
\hline $\mathrm{C}$ & $\mathrm{C}(\mathrm{C}-\mathrm{O}): \sim 286$ \\
& $\mathrm{C}(\mathrm{C}-\mathrm{C}): 285.0$ \\
& $\mathrm{C}(\mathrm{C}-\mathrm{P}): 286-287$ \\
\hline
\end{tabular}

\subsubsection{IL tribofilm on BAM}

3.2.2.1 IL tribofilm on BAM - SEM imaging and AES elemental mapping

Similarly to the characterization of the ZDDP tribofilm described above, the morphology, nanostructure, and composition of the IL tribofilm on the BAM coating are presented in Figs. 6-8. Unlike the ZDDP tribofilm that was 'visible' on the coating surface (zinc compounds appear 'bright' pads), the 
IL tribofilm showed little contrast in the SEM image (Fig. 6a, left). On the other hand, AES element mapping clearly revealed the IL tribofilm with Fe and P rich (Fig. 6a, middle and right). The individual element maps in Fig. $6 \mathrm{~b}$ provide additional insights for the IL tribofilm:

- $\quad$ P and C (from IL): The good match between P and C distributions implies that partially decomposed organophosphate(s) and/or phosphine oxide(s) (oxidized phosphonium cations) are enclosed in the IL tribofilm.

- Fe (from steel ball): Unlike the ZDDP that self-supplies $\mathrm{Zn}^{2+}$ in forming the tribofilm, the 'ashless' IL requires metal cations from elsewhere, e.g., wear debris from the steel ball. The strong correlations among $\mathrm{Fe}, \mathrm{O}$, and $\mathrm{P}$ maps indicate iron oxide(s) and phosphate(s) in the IL tribofilm. Compared to the ZDDP tribofilm, the iron concentration is higher: XPS compositiondepth profile suggests $\sim 3$ at.\% of oxidized iron in the IL tribofilm (Fig. $8 \mathrm{a}$ ) vs $\sim 0.5$ at.\% in the ZDDP tribofilm (Fig. 5a). Results indicate that the wear debris digestion mechanism [7] is applicable for IL tribofilm formation.

- $\quad \mathbf{T i}$ (from $\mathbf{T i B}_{2}$ of $\left.\mathbf{B A M}\right)$ ): The Ti map appears to overlaps with the O map, which suggest possible inclusion of titanium oxide(s) in the IL tribofilm (a similar observation to the ZDDP tribofilm).
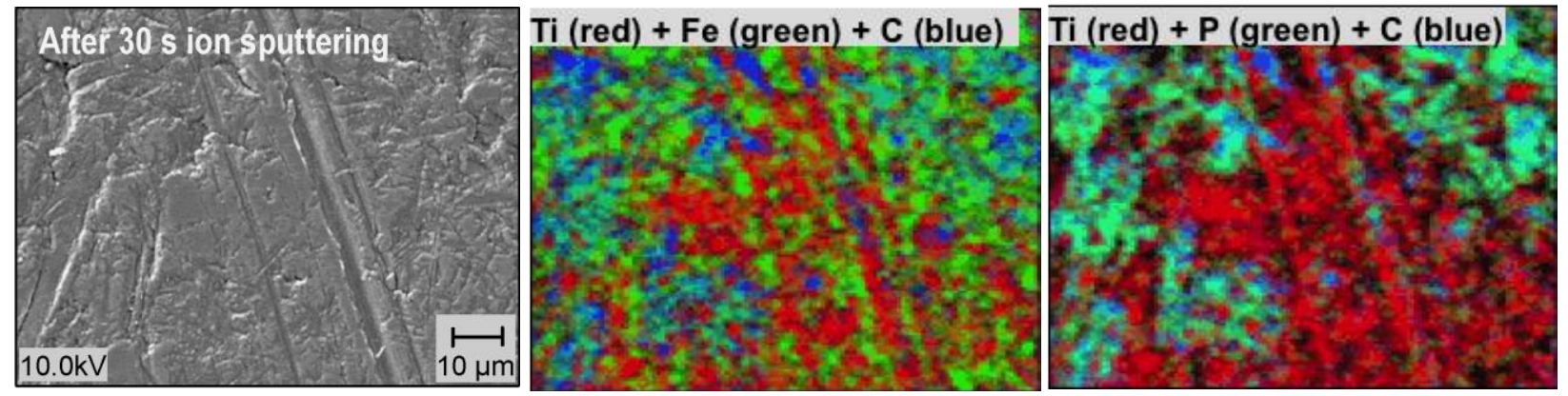

(a) IL tribofilm on BAM: SEM image and AES multi-element map after $30 \mathrm{~s}$ sputtering

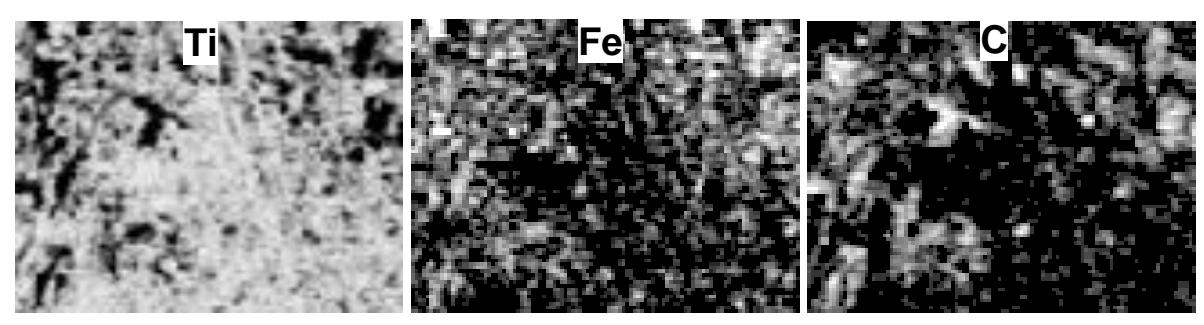




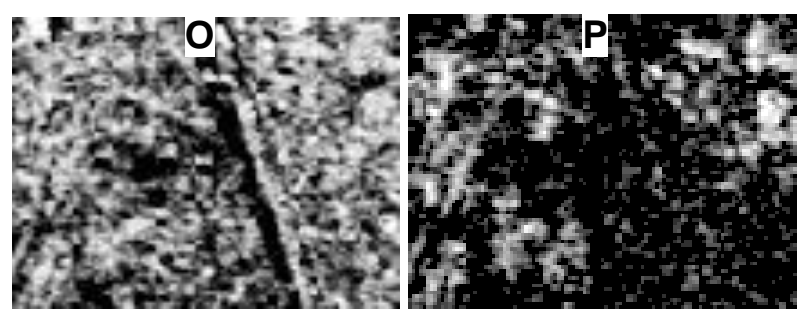

(b) IL tribofilm on BAM: AES individual element maps after $30 \mathrm{~s}$ sputtering

Fig. 6. SEM and AES examination of the tribofilm on the BAM worn surface lubricated by BO+IL.

The cross sectional TEM image and FFT pattern of the IL tribofilm on BAM are shown in Fig. 7. Similar to the ZDDP tribofilm (Fig. 4), the IL tribofilm is $\sim 50 \mathrm{~nm}$ thick and primarily in amorphous phase. (Note the gap-like white fringe in the tribofilm is simply an artifact arising from a slight underfocus of TEM imaging, which is necessary for an overall optimal imaging quality.)

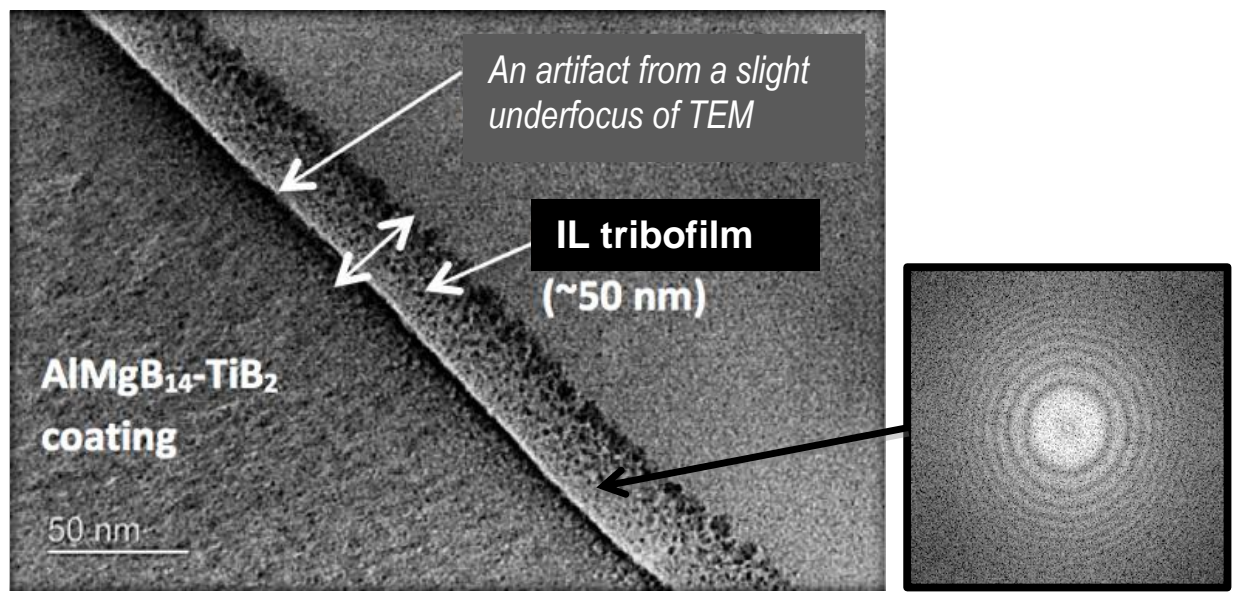

Fig. 7. Cross sectional TEM image (left) and the FFT pattern from an HRTEM image (right) revealing a 50 $\mathrm{nm}$ thick, amorphous tribofilm on the BAM worn surface lubricated by BO+IL.

The XPS composition-depth profile and core level spectra of the IL tribofilm on BAM are shown in Fig. 8. The nominal binding energies (excluding $\mathrm{Zn}$ and $\mathrm{S}$ ) in Table 4 are used to analyze the XPS core spectra. Main observations are summarized below:

- The composition-depth profile suggests a maximum thickness of 60-70 nm (Fig. 8a) for the IL tribofilm, slightly thicker than the ZDDP tribofilm (Fig. 5a). On the other hand, the BAM surface 
coverage by the IL tribofilm is about $75 \%$ (Fig. 8a), slightly lower than that by the ZDDP tribofilm (Fig. 5a).

- The $\sim 40$ at.\% of $\mathrm{O}$ and $\sim 5$ at.\% of $\mathrm{P}$ shown in the composition-depth profile in Fig. 8a (at the beginning of ion sputtering) along with their core level spectra in Fig. 8b suggest metal oxide(s) and phosphate(s) dominating the IL tribofilm.

- According to Fig. 8a, the concentration of iron ions is $\sim 3$ at.\%, notably higher than that $(\sim 0.5$ at.\%) in the ZDDP tribofilm. Similarly to that in the ZDDP tribofilm, iron detected in the top surface of the IL tribofilm (red, as received) appears to be in the $\mathrm{Fe}^{3+}$ phase while the iron signal from the inside the tribofilm (green, after $30 \mathrm{~s}$ sputtering) is dominated by $\mathrm{Fe}^{2+}$ and $\mathrm{Fe}^{0}$. Again, it is believed that the top tribofilm surface was further oxidized during post-test storage. The strong $\mathrm{Fe}^{0}$ signal suggests the inclusion of unreacted steel wear debris $(0.5-1$ at.\%) in the IL tribofilm.

- Similarly to the ZDDP tribofilms, $\mathrm{TiB}_{2}$ oxidation products were detected in the IL tribofilm, as shown in Fig. 8b, suggesting active involvement of the BAM surface in the tribofilm formation.
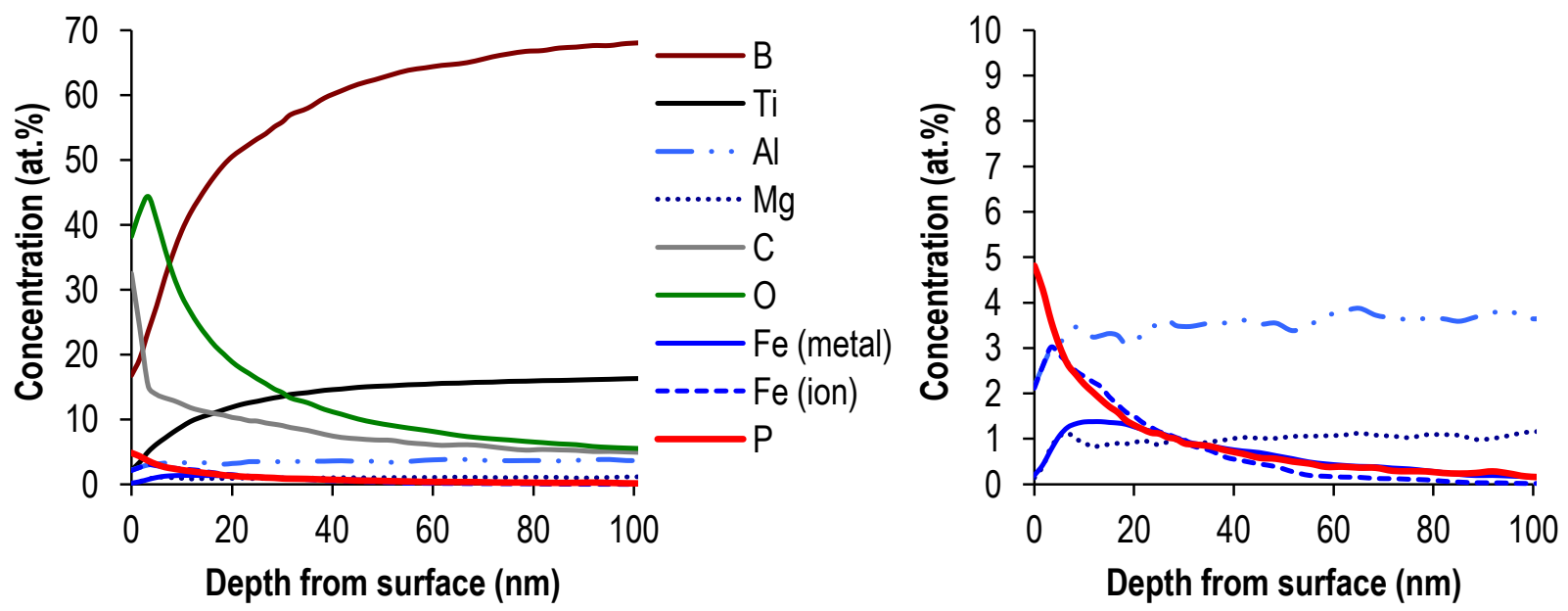

(a) IL tribofilm on BAM: Composition-depth profile (right: zoomed-in) 

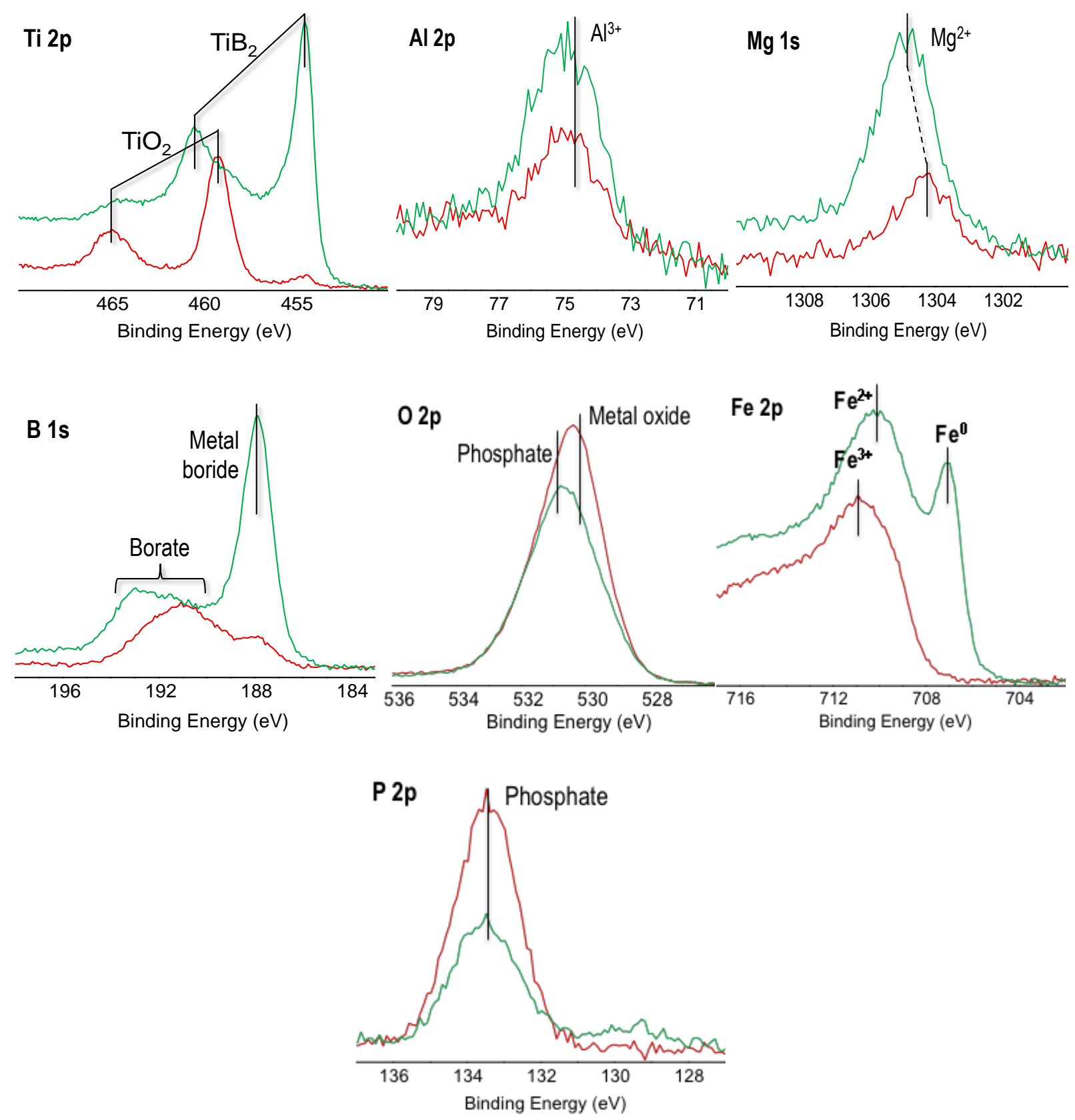

(b) IL tribofilm on BAM: Core level spectra (red: as received; green: after 30 s sputtering)

Fig. 8. XPS chemical analysis of the tribofilm on the BAM worn surface lubricated by BO+IL.

\subsection{Characterization of tribofilms on $\mathrm{TiB}_{2}$}

XPS chemical analysis was conducted on the tribofilms on the $\mathrm{TiB}_{2}$ coating wear scars, and the composition-depth profiles of the ZDDP and IL tribofilms on $\mathrm{TiB}_{2}$ (Fig. 9) and core level spectra (not 
shown here) are very similar to those on BAM (Figs. 5 and 8). For either ZDDP or IL, results suggest comparable surface coverage, film thicknesses, and chemical compositions for the tribofilms formed on the two boride coatings.
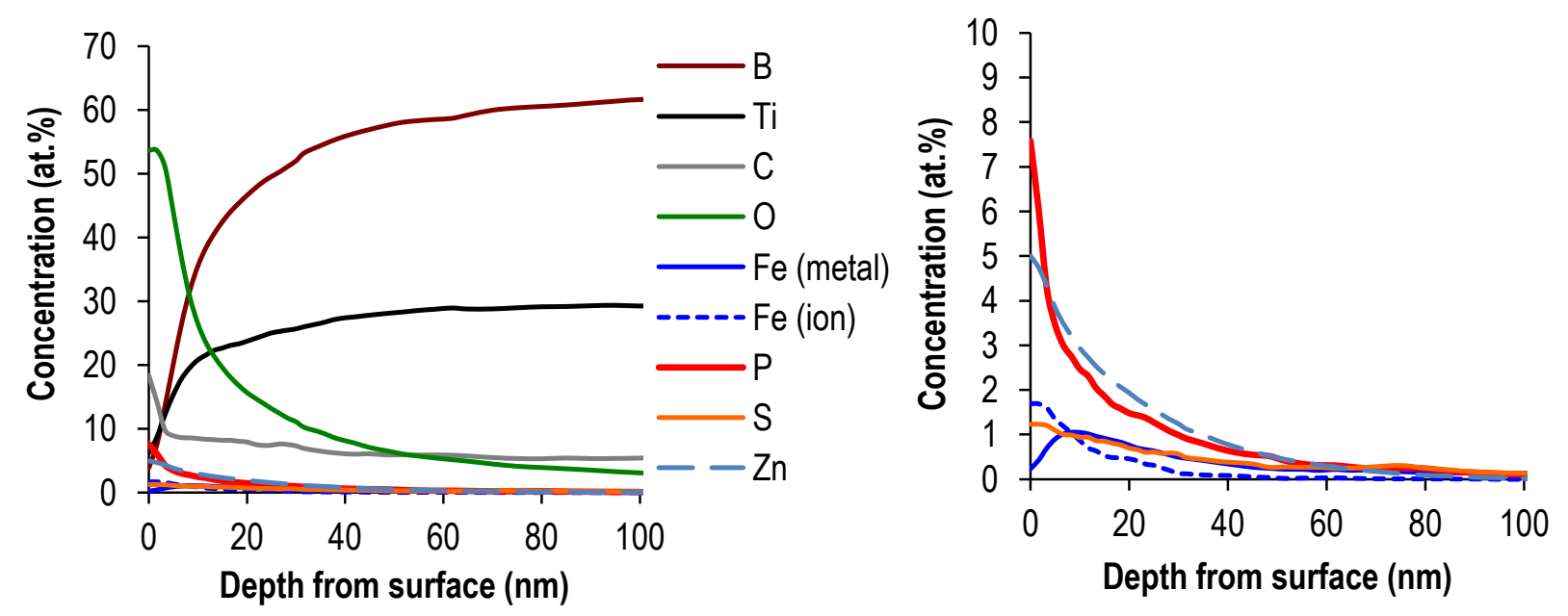

(a) ZDDP tribofilm on $\mathrm{TiB}_{2}$ : Composition-depth profile (right: zoomed-in)
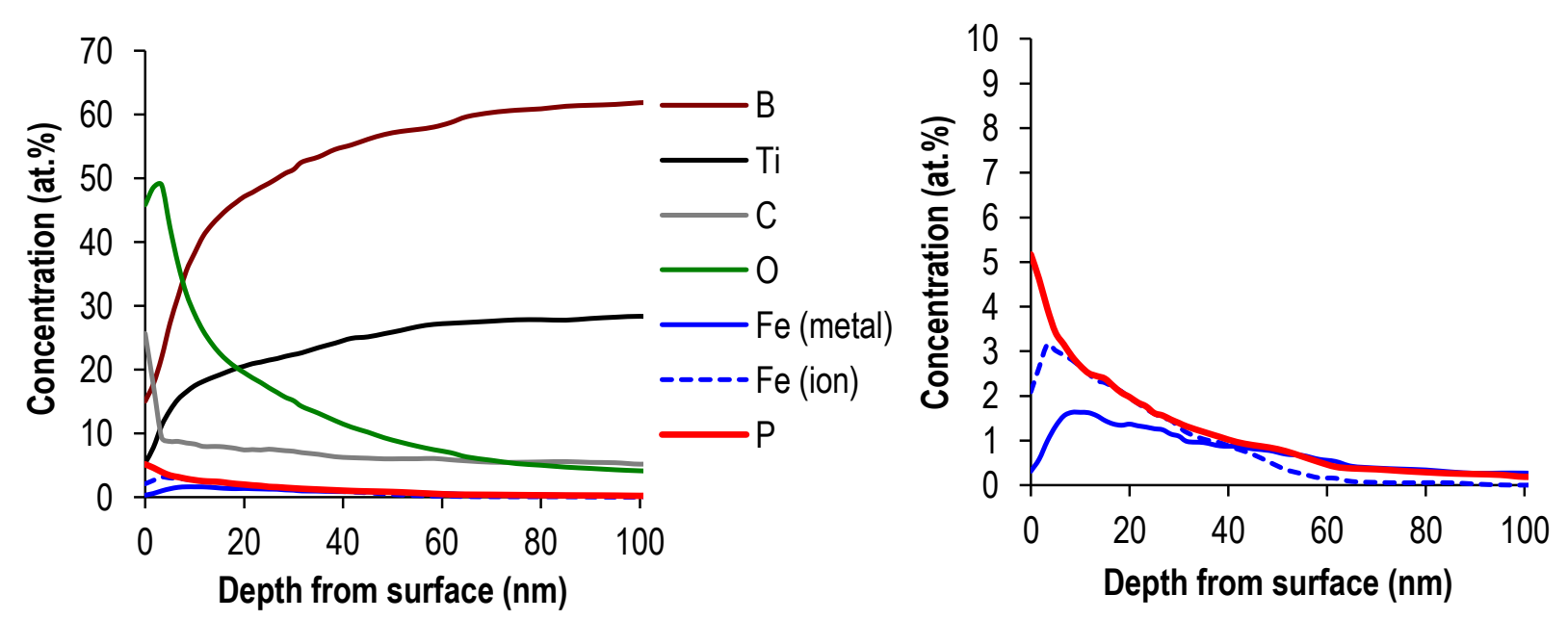

(b) IL tribofilm on $\mathrm{TiB}_{2}$ : Composition-depth profile (right: zoomed-in)

Fig. 9. XPS chemical analysis of the tribofilms on $\mathrm{TiB}_{2}$ worn surfaces lubricated by BO+ZDDP and BO+IL. 


\subsection{Characterization of tribofilms on DLC}

It has been reported to be difficult to form a thick ZDDP tribofilm on hydrogenated DLC (a-C:H) [12]. Results in this study concurred this. The tribofilms on the DLC coating significantly distinguish themselves from those on the two boride coatings as discussed below:

- The ZDDP and IL tribofilms seem to cover $\sim 25 \%$ and $\sim 20 \%$ areas of the worn DLC surfaces, respectively, according to the SEM images, AES element maps, and XPS composition-depth profiles shown in Figs. 10-12. This is much lower than the tribofilm surface coverage (75-80\%) on the two boride coatings.

- The maximum thicknesses of the ZDDP and IL tribofilms on DLC seem to be $\sim 25$ and $\sim 30 \mathrm{~nm}$, respectively, as suggested by the XPS composition-depth profiles in Fig. 12. This is notably thinner than that on either boride coating. Cross sectional TEM was unsuccessful in imaging the tribofilms, possibly because the FIB sampling was conducted on a surface area with no tribofilm (understandable considering the relatively low surface coverage).

- For the ZDDP tribofilm on DLC, there is a good match between $\mathrm{Zn}$ and $\mathrm{O}$ maps, but no clear distribution pattern for $\mathrm{P}$ and $\mathrm{S}$, as shown in Fig. 10b. For the IL tribofilm on DLC, Fe and O maps overlap well, but the P content seems more or less randomly distributed (Fig. 11b). The pattern-less distribution of the lighter elements ( $\mathrm{P}$ and $\mathrm{S}$ from ZDDP or P from IL) may be caused by the residual ZDDP or IL absorbed on the DLC surface after tribo-testing. The AES element maps on the DLC coating were acquired without sputtering to preserve the tribofilms in lieu of their low thickness. (In contrast, the AES individual element mapping on the boride surfaces was conducted after $30 \mathrm{~s}$ sputtering to eliminate surface contaminants.)

- Analysis of the core level spectra (not shown here) indicated that the ZDDP tribofilm on DLC are composed of zinc/iron oxides/phosphates, zinc sulfide, and a small amount of metallic iron. The IL tribofilm on DLC contains iron oxides/phosphates along with metallic iron.

- There was no evidence of interactions between the anti-wear additives and the DLC surface. 

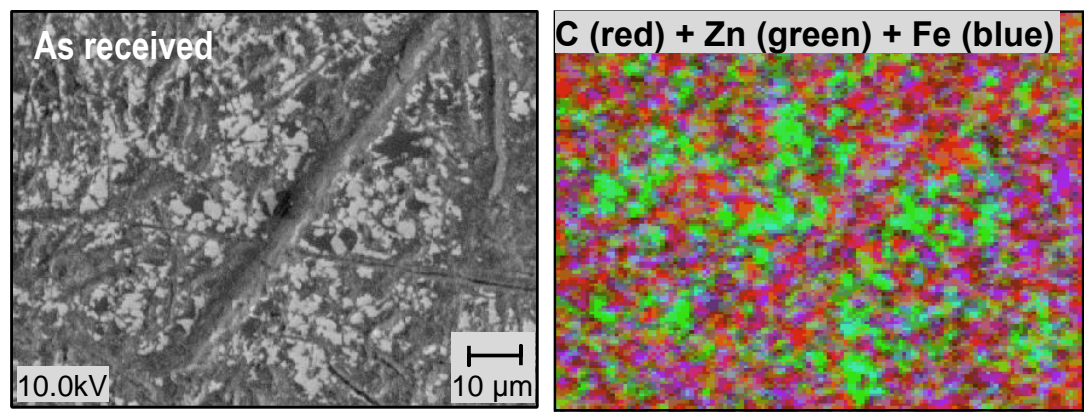

(a) ZDDP tribofilm on DLC: SEM image and AES multi-element map (no sputtering)
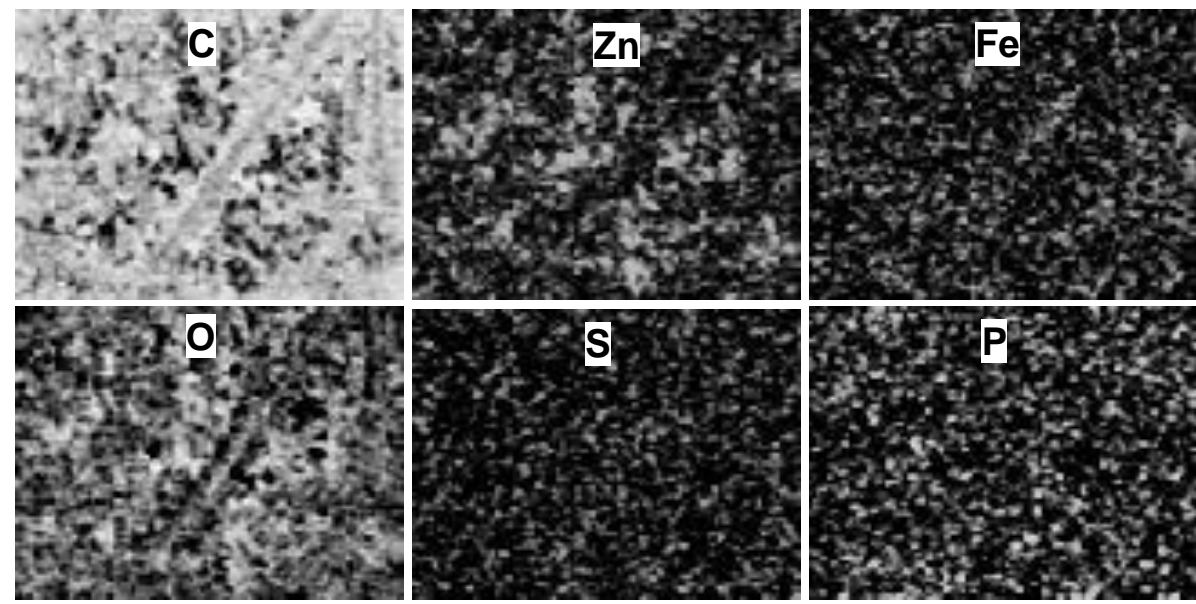

(b) ZDDP tribofilm on DLC: AES individual element maps (no sputtering)

Fig. 10. SEM and AES examination of the tribofilm on the DLC worn surface lubricated by BO+ZDDP.
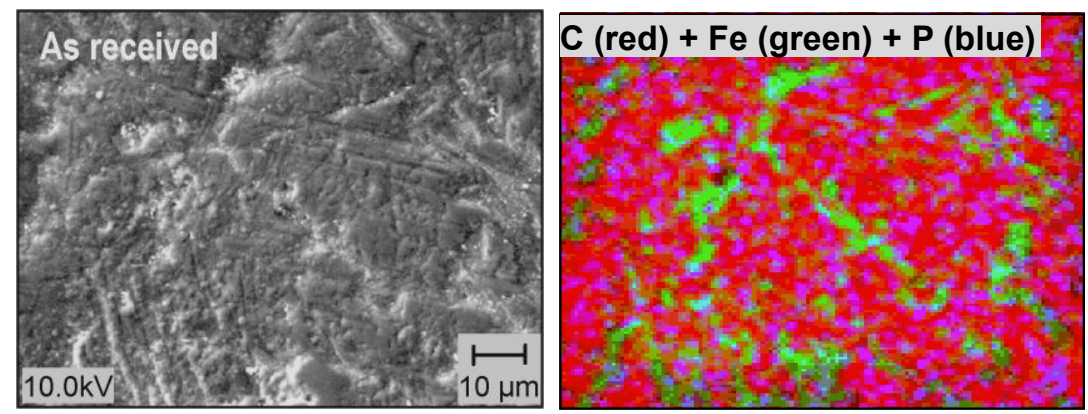

(a) IL tribofilm on DLC: SEM image and AES multi-element map (no sputtering) 


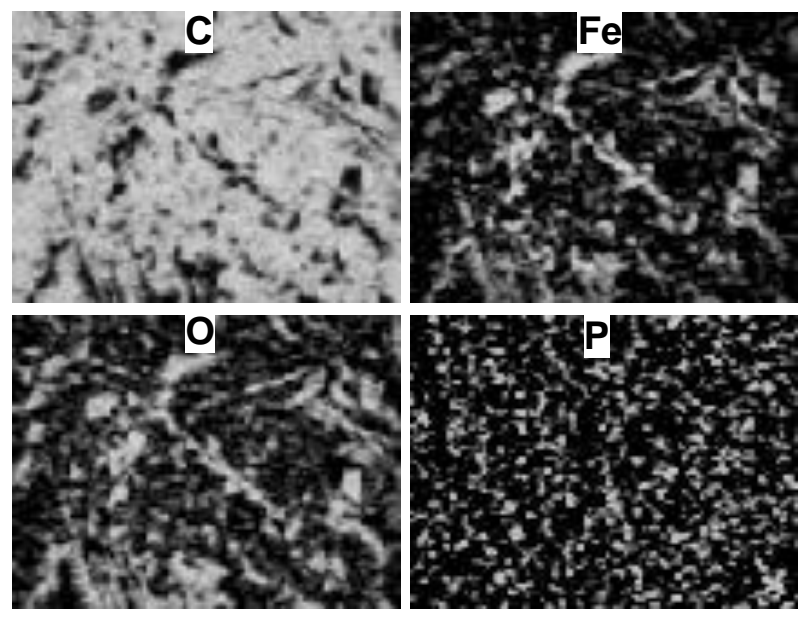

(b) IL tribofilm on DLC: AES individual element maps (no sputtering)

Fig. 11. SEM and AES examination of the tribofilm on the DLC worn surface lubricated by BO+IL.
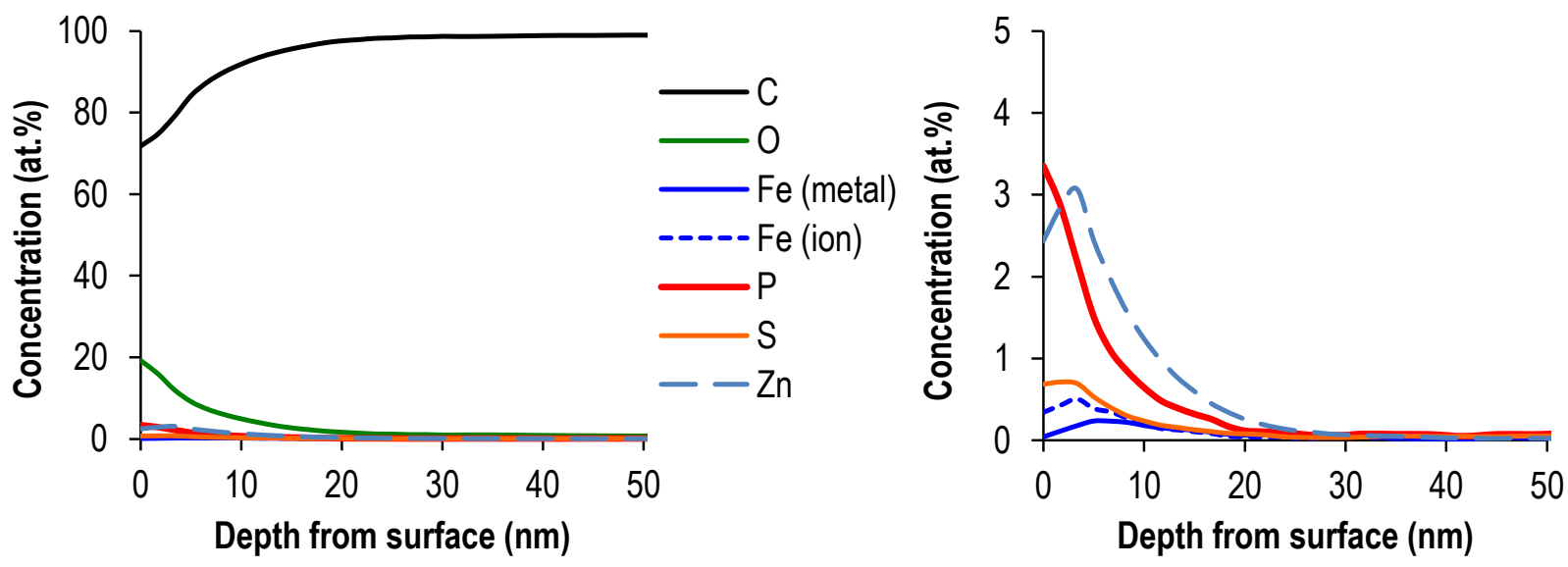

(a) ZDDP tribofilm on DLC: Composition-depth profile (right: zoomed-in)
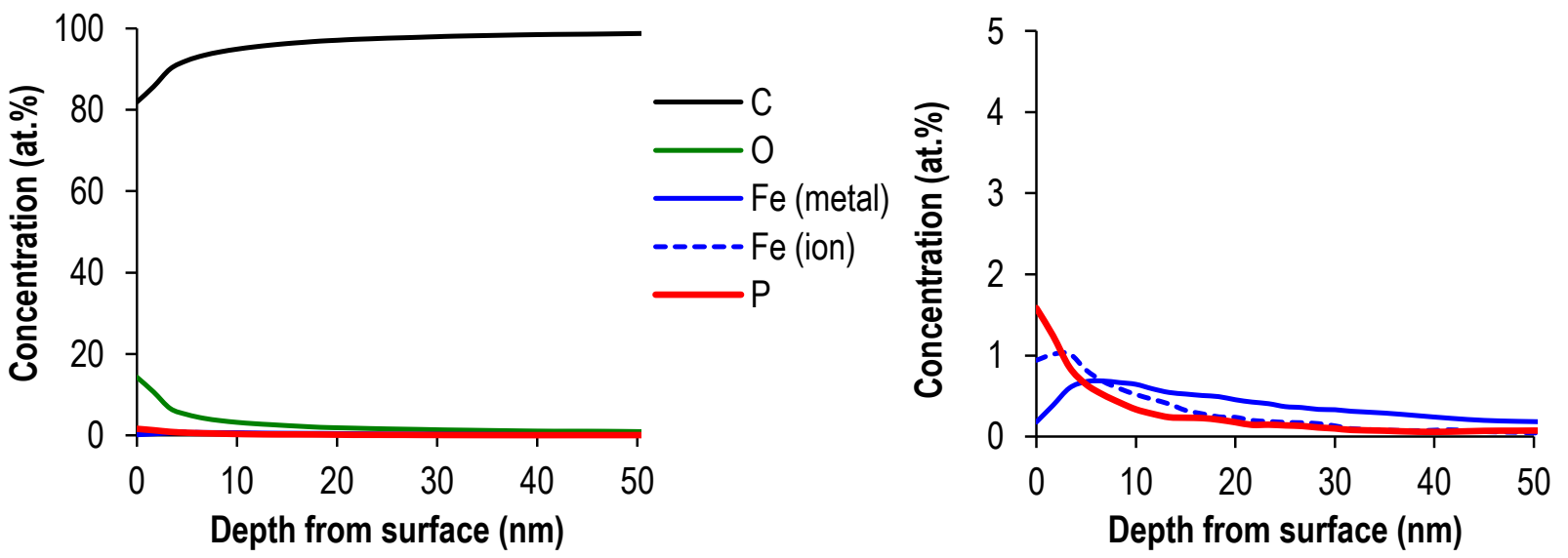

(b) IL tribofilm on DLC: Composition-depth profile (right: zoomed-in)

Fig. 12. XPS chemical analysis of the tribofilms on DLC worn surfaces lubricated by BO+ZDDP (a) and $\mathrm{BO}+\mathrm{IL}(\mathrm{b})$, respectively. 


\subsection{Insights of ZDDP and IL tribofilm formation mechanisms}

It is generally accepted that a ZDDP tribofilm is formed via complex chemical reactions among decomposed ZDDP species and the contact surface [4-6,8]. The tribofilm formation process for ILs, which do not self-supply metallic cations, is believed to primarily rely on tribochemical reactions with the contact surfaces [16-20,25-30]. Although Martin et al. [7] proposed a sound mechanism of wear debris digestion in ZDDP tribofilm formation, there was ambiguity for the source of iron in the ferrous-ferrous contact studied in his work.

In this study, the presence of iron (both metallic and oxide phases) in the tribofilms on the nonferrous coating surfaces unambiguously supports the wear debris digestion mechanism, and suggests that such a mechanism is applicable and important for both ZDDP and ILs. Further, the better match between Fe and P maps than that between Zn and P in the ZDDP tribofilm agrees well with Martin's model based on chemical hardness: iron oxide reacting with zinc phosphate to produce iron phosphate and zinc oxide.

On the other hand, the detection of titanium oxides in the tribofilms on boride coatings is direct evidence of involvement of the boride surface in tribofrilm formation, which is believed to responsible to the tribofilms' relatively high surface coverage and thickness. The tribofilm on DLC appear to be thin and isolated patches, which is likely attributed to the lack of chemical bonding with the substrate.

Results here suggest that wear debris digestion and contact surface reaction both are critical in tribofilm formation: the former process is responsible in forming the bulk of the tribofilm and the latter provides strong bonding of the tribofilm to the contact surface.

\section{Conclusions}

A secondary ZDDP and a phosphonium-phosphate ionic liquid were used as AW additives in a SAE 0W-30 base oil to lubricate three hard coatings: $\mathrm{AlMgB}_{14}-\mathrm{TiB}_{2}, \mathrm{TiB}_{2}$, and $\mathrm{DLC}(\mathrm{a}-\mathrm{C}: \mathrm{H})$ against a bearing steel ball. The wear scars on the coating surfaces were characterized with following key observations:

- ZDDP and IL tribofilms were formed on the boride and DLC coatings with various surface coverage and thicknesses. While the tribofilms on the two boride coatings cover the contact area 
by $75-80 \%$ and are up to $60-70 \mathrm{~nm}$ thick, those on DLC have a much less surface coverage (20$30 \%)$ and a much lower thickness $(<25 \mathrm{~nm})$.

- Similar to tribofilms on ferrous alloys, the ZDDP and IL tribofilms on all three coatings are nanostructured composites of metal oxides, metal phosphates, sulfides (ZDDP only), and metallic iron nanoparticles (wear debris of the steel ball).

- The presence of iron compounds (in both metallic and oxidized forms) in the ZDDP and IL tribofilms on the non-metallic coatings indicates involvement of the steel ball wear debris in the tribofilm formation. The nice overlap of Fe and $\mathrm{P}$ maps further implies tribochemical reactions between the iron wear debris and phosphate additives. This supports the wear particle digestion theory proposed by Martin et al. for ZDDP tribofilm formation [7] and suggests it is applicable to IL tribofilm formation.

- For the boride coatings, oxidation products of $\mathrm{TiB}_{2}$ were possibly involved in the tribofilm formation, which could improve the bonding between the tribofilm and the boride surface. In contrast, there was no evidence of interactions between the anti-wear additives and the hydrogenated DLC. This may help explain the thicker and higher surface coverage of the tribofilms on the boride coatings than those on DLC.

- Unambiguous evidences for two critical processes in tribofilm formation have been obtained in this study: wear debris digestion and contact surface reaction. The former process is believed to be responsible in forming the bulk of the tribofilm and the latter generates strong interface bonding to the substrate.

\section{Acknowledgements}

The authors thank Dr. Y. Zhou from ORNL for cross-sectional SEM imaging and EDS elemental mapping of the coatings, D.W. Coffey from ORNL for TEM sample preparation, Dr. M. Chi from ORNL for discussion in TEM analysis, C. Higdon from Eaton for providing the boride coatings, P. Kay from 
HEF for providing the DLC coating, and Dr. E. Bardasz from Lubrizol for providing the ZDDP, respectively. Research sponsored by the Vehicle Technologies Office, Office of Energy Efficiency and Renewable Energy, U.S. Department of Energy (DOE).

Notice: This report has been authored by UT-Battelle, LLC, under Contract No. DE-AC05-00OR22725 with the U.S. Department of Energy. The United States Government retains and the publisher, by accepting the article for publication, acknowledges that the United States Government retains a nonexclusive, paid-up, irrevocable, world-wide license to publish or reproduce the published form of this manuscript, or allow others to do so, for United States Government purposes.

\section{References}

[1]. J.-E. Sundgren, H.T.G. Hentzell, A review of the present state of art in hard coatings grown from the vapor phase, Journal of Vacuum Science \& Technology A 4 (1986) 2259-2279.

[2]. L. Wu, X. Guo, J. Zhang, Abrasive Resistant Coatings-A Review, Lubricants 2 (2014) 66-89.

[3]. L.R. Rudnick, Lubricant Additives - Chemistry and Applications, Marcel Dekker, 2003.

[4]. H. Spikes, The history and mechanisms of ZDDP, Tribology Letters 17 (2004) 469-489.

[5]. M.A. Nicholls, Do, T., Norton, P.R., Kasrai, M., Bancroft, G.M., Review of the lubrication of metallic surfaces by zinc dialkyl-dithiophosphates, Tribol. Int. 38, 15-39 (2005).

[6]. Z. Yin, M. Kasrai, M. Fuller, G.M. Bancroft, K. Fyfe, K.H. Tan, Application of soft X-ray absorption spectroscopy in chemical characterization of antiwear films generated by ZDDP Part I: the effects of physical parameters, Wear 202 (1997) 172.

[7]. J.M. Martin, Antiwear mechanisms of zinc dithiophosphate: a chemical hardness approach, Tribology Letters 6 (1999) 1-8.

[8]. N.J. Mosey, M.H. Muser, T.K. Woo, Molecular mechanisms for the functionality of lubricant additives, Science 307 (2005) 1612-1615.

[9]. K. Ito, J.-M. Martin, C. Minfray, K. Kato, Low-friction tribofilm formed by the reaction of ZDDP on iron oxide, Tribol. Int. 39 (2006) 1538.

[10].J. Qu, P.J. Blau, J.Y. Howe, H.M. Meyer III, Oxygen diffusion enables anti-wear boundary film formation on titanium surfaces in zinc-dialkyl-dithiophosphate (ZDDP)-containing lubricants, Scripta Materialia 60 (2009) 886-889. 
[11].K. Topolovec-Miklozica, F. Lockwoodb, H. Spikes, Behaviour of boundary lubricating additives on DLC coatings, Wear 265 (2008) 1893-1901.

[12].B. Vengudusamy, J.H. Green, G.D. Lamb, H.A. Spikes, Tribological properties of tribofilms formed from ZDDP in DLC/DLC and DLC/steel contacts, Tribology International 44 (2011) 165-174.

[13].T. Haque, A. Morina, A. Neville, R. Kapadia, S. Arrowsmith, Non-ferrous coating/lubricant interactions in tribological contacts: Assessment of tribofilms, Tribology International 40 (2007) $1603-1612$.

[14].Z.-B. Cai, H.M. Meyer, C. Ma, M. Chi, H. Luo, J. Qu, Comparison of the tribological behavior of steel-steel and $\mathrm{Si}_{3} \mathrm{~N}_{4}-$ steel contacts in lubricants with ZDDP or ionic liquid, Wear 319 (2014) 172183.

[15].C.F. Ye, W.M. Liu, Y.X. Chen, L.G. Yu, Room Temperature ionic liquids: A novel versatile lubricant, Chemical Communications (2001) 2244-2245.

[16].F. Zhou, Y. Liang, W. Liu, Ionic liquid lubricants: designed chemistry for engineering applications, Chem. Soc. Rev. 38 (2009) 2590-2599.

[17]. I. Minami, Ionic liquids in tribology, Molecules (Basel, Switzerland) 14 (2009) 2286-2305.

[18].M. Bermúdez, A.-E. Jiménez, J. Sanes, F.-J. Carrión, Ionic Liquids as Advanced Lubricant Fluids, Molecules 14 (2009) 2888-2908.

[19].A. Somers, P. Howlett, D. MacFarlane, M. Forsyth, A Review of Ionic Liquid Lubricants. Lubricants 1 (2013) 3-21.

[20].J. Qu, M.F. Chi, H.M. Meyer III, P.J. Blau, S. Dai, H.M. Luo, Nanostructure and composition of tribo-boundary films formed in ionic liquid lubrication, Tribol. Lett. 43 (2011) 205-211.

[21].K. Mistry, M.F. Fox, M. Priest, Lubrication of an electroplated nickel matrix silicon carbide coated eutectic aluminium-silicon alloy automotive cylinder bore with an ionic liquid as a lubricant additive, J. Eng. Tribol. 2009, 223, 563-569

[22]. R. Gonzalez, A. Hernandez Battez, D. Blanco, J.L. Viesca, A. Fernandez-Gonzalez, Lubrication of TiN, CrN and DLC PVD coatings with 1-butyl-1-methylpyrrolidinium tris(pentafluoroethyl)trifluorophosphate, Tribology Letters 40 (2010) 269-277.

[23].J. Qu and H. Luo, "Ionic liquids containing symmetric quaternary phosphonium cations and phosphorus-containing anions, and their use as lubricant additives," U.S. Patent Application $14 / 184,754$.

[24].J. Qu, H. Luo, Y. Zhou, J. Dyck, and T. Graham, "Ionic liquids containing quaternary phosphonium cations and carboxylate anions, and their use as lubricant additives," U.S. Patent Application $14 / 444,029$.

[25].J. Qu, D.G. Bansal, B. Yu, J. Howe, H. Luo, S. Dai, H. Li, P.J. Blau, B.G. Bunting, G. Mordukhovich, D.J. Smolenski, Anti-wear performance and mechanism of an oil-miscible ionic liquid as a lubricant additive, ACS Applied Materials \& Interfaces 4 (2) (2012) 997-1002. 
[26]. B. Yu, D.G. Bansal, J. Qu, X. Sun, H. Luo, S. Dai, P.J. Blau, B.G. Bunting, G. Mordukhovich, D.J. Smolenski, Oil-Miscible and non-corrosive phosphonium-based ionic liquids as candidate lubricant additives, Wear 289 (2012) 58-64.

[27].J. Qu, H. Luo, M. Chi, C. Ma, P.J. Blau, S. Dai, M.B. Viola, Comparison of an oil-miscible ionic liquid and ZDDP as a lubricant anti-wear additive, Tribology International 71 (2014) 88-97.

[28]. A.E. Somers, B. Khemchandani, P.C. Howlett, J. Sun, D.R. MacFarlane, M. Forsyth, Ionic liquids as antiwear additives in base oils: influence of structure on miscibility and antiwear performance for steel on aluminum, ACS Applied Materials \& Interfaces 5 (2013) 11544-11553.

[29]. Y. Zhou, J. Dyck, T. Graham, H. Luo, D.N. Leonard, J. Qu, Ionic liquids composed of phosphonium cations and organophosphate, carboxylate, and sulfonate as novel lubricant anti-wear additives, Langmuir 30(44) (2014) 13301-13311.

[30].W.C. Barnhill, J. Qu, H. Luo, H.M. Meyer III, C. Ma, M. Chi, B.L. Papke, Phosphoniumorganophosphate ionic liquids as lubricant additives: effects of cation structure on physicochemical and tribological characteristics, ACS Applied Materials \& Interfaces DOI: 10.1021/am506702u.

[31].E. Matrubara, Y. Waseda, S. Takeda, Y. Taga, Structural study of $\mathrm{TiB}_{2}$ film by grazing incidence Xray diffraction, Thin Solid Films 186 (1984) L33-L37.

[32].R. Wiedemann, H. Oettel and M. Jerenz, Structure of deposited and annealed $\mathrm{TiB}_{2}$ layers, Surface Coatings and Technology 97 (1997) 313.

[33].M. Berger, Thick Physical Vapour Deposited $\mathrm{TiB}_{2}$ Coatings, Surface Engineering, 18 (2002) 219223.

[34].N. Panich, P. Wangyao, S. Hannongbua, P. Sricharoenchai, Y. Sun, Tribological study of nanomultilayered ultra-hard coatings based on $\mathrm{TiB}_{2}$, Reviews on Advanced Materials Science 13 (2006) 117-124.

[35]. A. Grilla, V. Patela, B.S. Meyerson, Optical and tribological properties of heat-treated diamond-like carbon, Journal of Materials Research 5 (11) (1990) 2531-2537.

[36]. A. Grill, Review of the tribology of diamond-like carbon, Wear 168 (1-2) (1993) 143-153.

[37]. A. Grill, Diamond-like carbon: State of the art, Diamond and Related Materials 8 (2-5) (1999) 428434.

[38].J.A. Heimberg, K.J. Wahl, I.L. Singer, A. Erdemir, Superlow friction behavior of diamond-like carbon coatings: Time and speed effects, Applied Physics Letters 78 (2001) 2449-2251.

[39].Y. Tian, A. Constant, C.C. Lo, J.W. Anderegg, A.M. Russell, J.E. Snyder, Journal of Vacuum Science \& Technology A 21 (2003) 1055.

[40].J. Qu, P.J. Blau, D. Zhu, B.A. Cook, A.A. Elmoursi, Tribological Characteristics of $\mathrm{AlMgB}_{14}$ and Nanocomposite $\mathrm{AlMgB}_{14}-\mathrm{TiB}_{2}$ Superhard Coatings, IJTC2008-71176, Proceedings of IJTC2008 STLE/ASME International Joint Tribology Conference, Miami, FL, USA, October 20-22, 2008. 
[41].B.A. Cook, J.L. Harringa, J.W. Anderegg, A.M. Russell, J. Qu, P.J. Blau, C.B. Higdon, A.A. Elmoursi, Analysis of wear mechanisms in low friction $\mathrm{AlMgB}_{14}-\mathrm{TiB}_{2}$ coatings, Surface \& Coatings Technology 205 (2010) 2296-2301.

[42].C. Higdon, B. Cook, J. Harringa, A. Russell, J. Goldsmith, J. Qu, P. Blau, Friction and wear mechanisms in $\mathrm{AlMgB}_{14}-\mathrm{TiB}_{2}$ nanocoatings, Wear 271 (2011) 2111-2115.

[43].C. Yan, J.C. Qian, T.W. Ng, Z.F. Zhou, K.Y. Li, W.J. Zhang, I. Bello, L. Martinu, J.E. KlembergSapieh, Sputter deposition of hard quaternary Al-Mg-B-Ti nanocomposite films, Surface and Coatings Technology 232 (2013) 535-540.

[44]. SAE J300, Engine Oil Viscosity Classification, SAE International, April 2013.

[45].B.J. Hamrock, D. Dowson, Ball Bearing Lubrication-The Elastohydrodynamics of Elliptical Contacts; John Wiley \& Sons: New York, 1981. 